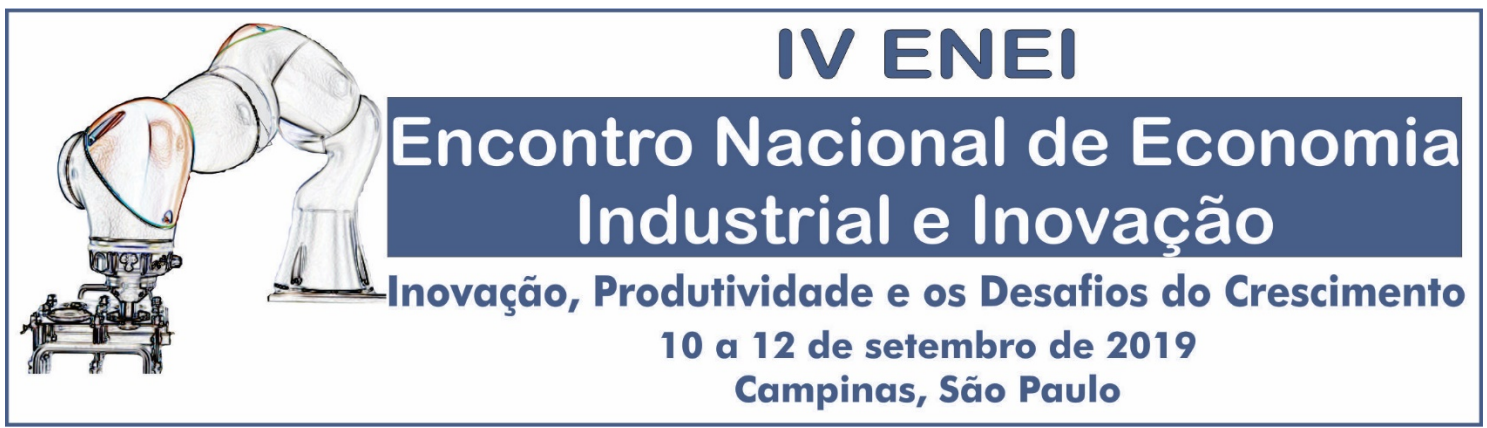

\title{
AMPLIAÇÃO DE CAPACIDADES TECNOLÓGICAS DE EMPRESAS LATECOMERS COMO FUNDAMENTO DA COMPLEXIDADE ECONÔMICA: ESTUDO DE CASO DA WEG
}

S.A.

\author{
Prof. Dr. Aulo Pércio Vicente Nardo ${ }^{1}$ \\ Prof. Dr. Pablo Felipe Bittencourt ${ }^{2}$
}

\begin{abstract}
RESUMO
O objetivo do artigo é destacar o acúmulo de certo nível de capacidade (capabilitie) tecnológica como fator determinante da diversificação produtiva que aumenta a complexidade econômica. Para isso, sob a perspectiva neoschumpeteriana da firma, o artigo apresenta analise dos processos de aprendizagem e de construção de competências tecnológicas que permitiram diversificação produtiva da WEG, empresa brasileira, uma das líderes tecnológicas de segmentos em que atua no mundo. A pesquisa de campo centra-se nas diversificações de motores para geradores elétricos e de geradores elétricos para aerogeradores. Os resultados revelaram que, a partir de uma postura empresarial agressiva de aprendizagem, um nível intermediário avançado de capacidade inovadora foi altamente relevante aos processos de diversificação avaliados. Neste sentido, a investigação permitiu levantar a hipótese de que a diversificação que aumenta a complexidade produtiva, tem como um de seus fundamentos a ofensividade tecnológica empresarial entendida como uma constante busca ao longo do tempo por acumular capacidade de gerar e gerir mudança tecnológica.
\end{abstract}

PALAVRAS CHAVES: Ofensividade estratégica; Mecanismos de Aprendizagem; Capacidades Tecnológicas; Diversificação.

\footnotetext{
${ }^{1}$ Doutor em economia pela Universidade Federal de Santa Catarina - UFSC. Atualmente é Supervisor de Disciplina no Núcleo de Ensino a Distância - NEAD da UNIASSELVI, campus Indaial/SC. E-mail: aulo.nardo@uniasselvi.com.br;

2 Doutor em economia pela Universidade Federal Fluminense - UFF. Atualmente é Professor Adjunto da Universidade Federal de Santa Catarina - UFSC, Campus Florianópolis/SC, e-mail: pablofelipe.bittencourt@gmail.com.
} 


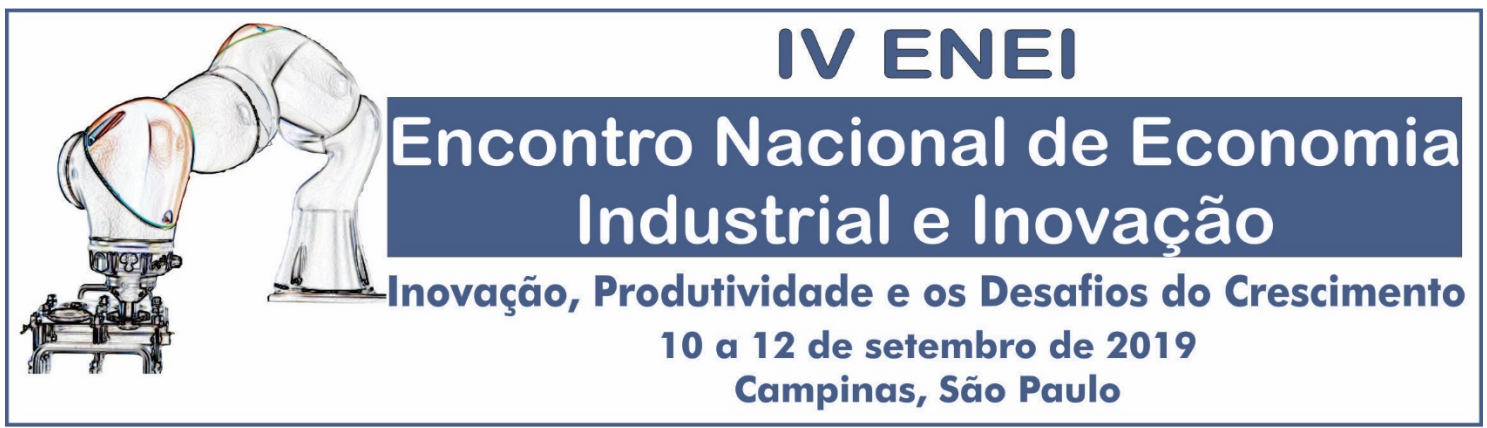

\section{INTRODUÇÃO}

A inspiração para a pesquisa que sustenta esse artigo (autor, 2018), adveio das evidencias empíricas recentemente sintetizadas no Atlas da Complexidade, cuja elaboração do índice de complexidade e discussões sobre sua relação com o desempenho das economias nacionais e regionais encontram-se, por exemplo em Hausmann e Klinger (2007), Hidalgo e Hausmann (2009), Hausman, Hwang e Rodrik (2006) e Hausmann et. al. (2014). Essa linha de contribuições sustenta que os diferentes níveis de renda dos países encontram como causa a capacidade de produzir produtos complexos. Assim, os países mais desenvolvidos seriam capazes de produzir produtos mais complexos basicamente porque seus trabalhadores, por possuirem capacidades similares, migram com maior facildade para atividades produtivas afins e, por consequência, a indústria migra com maior facilidade para produtos mais complexos ao longo do tempo. Há, portanto, uma tendência de reforço.

As eloquentes evidências, apresentadas no espaço produto (HIDALGO ET. AL., 2007; HAUSMANN ET. AL.,2014), ainda são limitadas para explicar de onde surgem as capacidades dos trabalhadores, capazes de explicar o cathing up de países como Japão e Coréia do Sul (CHANG e ANDREONI, 2016). Os autores, apontam capacidades de forma genérica, relacionadas aos direitos de propriedade, regulação, infraestrutura e competências laborais (incluindo conhecimento tácito). Nesse sentido, a perspectiva da complexidade ainda apresenta debilidade por não estabelecer uma conexão teórica ou mesmo empírica entre construção de capacidades e complexidade. 


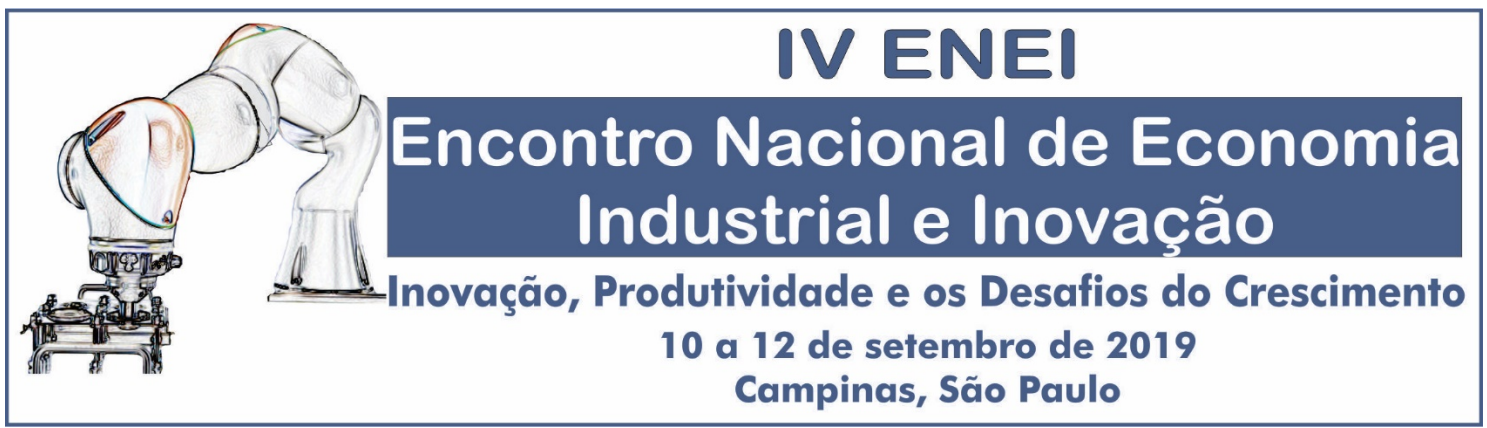

Esse artigo fornece uma evidência empírica de cunho neoschumpeteriano sobre o papel do acúmulo de capacidade tecnológica no processo de diversificação produtiva que aumenta a complexidade. Para isso, utiliza-se de estudo de caso da WEG, empresa multinacional brasileira do setor de equipamentos elétricos, ofertante de ampla gama de produtos. Pode-se notar que a diversificação que aumentou a complexidade produtiva em duas oportunidades foi precedida por esforço de acúmulo de capacidade de inovação em um nível significativo, que foi medido seguindo-se a evolução conceitual encontradas em Lall (1992), Bell e Pavitt (1995) e Ariffin e Figueiredo (2003). As evidências apontam que esse nível foi "muito importante" ao aproveitamento de economias de escopo dinâmicas (Teece, 1980;1982), essenciais à diversificação. Além disso, notou-se que tal acúmulo de capacidade foi fruto da intenção deliberada da empresa de ampliar sua capacidade de gerar e gerir a mudança tecnológica na tecnologia anterior, o que se revela pela agressividade com que se engajou em processos de aprendizagem envolvendo mecanismos internos e externos à firma (Lundval, et.all., 2010), num típico movimento de cathing up ao nível da empresa. Ariffin e Figueiredo (2003), Ariffin (2010), Bell e Figueiredo (2012) e Figueiredo (2000, 2004, 2013).

As referências teórica para a investigação empírica, apresentadas na próxima seção, estão sub-divididas em três itens da próxima seção e referem-se, respectivamente, (i) ao níveis de acúmulo de capacidade tecnológica de empresas latecomers, ou seja, inseridas em países em desenvolvimento (Lall, 1992), (Bell e Pavitt, 1995); (ii) aos processos de diversificação produtiva (Penrose, 1959 e Tecce, 1980 e 1982), assim como, (iii) à discussão sobre complexidade. A seção três apresenta os aspectos 


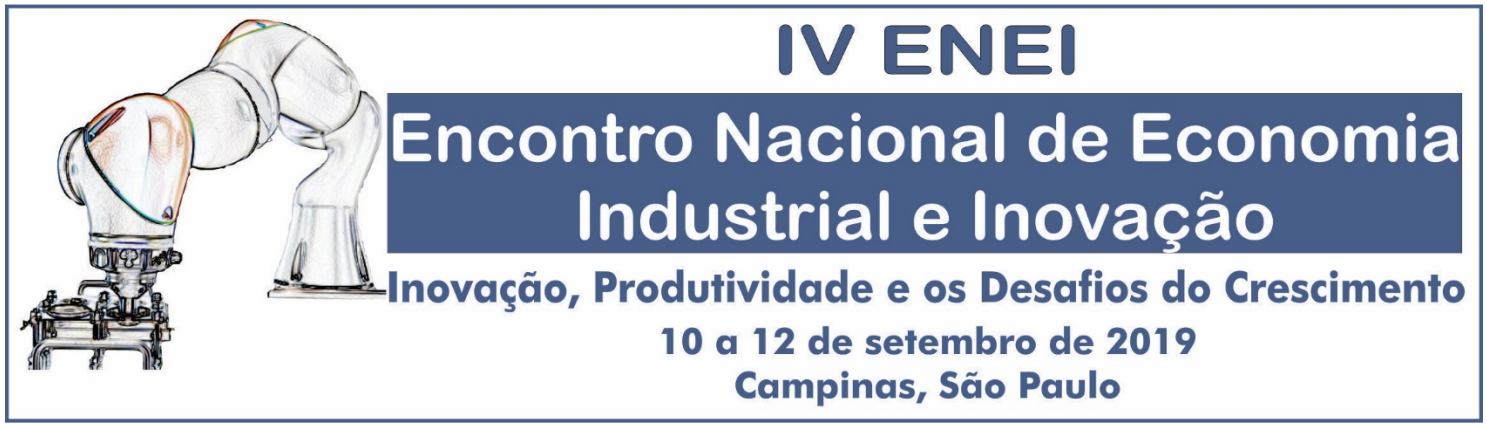

metodológicos da pesquisa. A seção 4 é a discussão dos resultados e a seção 5 é conclusiva.

2. ACUMULO DE CAPACIDADES TECNOLÓGICAS, DIVERSIFICAÇÃO PRODUTIVA E COMPLEXIDADE ECONÔMICA.

\subsection{ACÚMULO DE CAPACIDADES TECNOLÓFICAS DE FIRMAS LATE} COMMERS

Autores vinculados à tradição neoschumpeteriana da firma costumam dar alta relevância a ativos intangíveis como causas dos diferenciais de desempenho das firmas. Em quaisquer perspectivas as capacidades assemelham-se a noção de estoque de conhecimentos, enquanto que o aprendizado é o fluxo pelo qual absorvem-se conhecimentos.

Para Bell e Figueiredo (2012) o termo aprendizado associa-se a esforços específicos das empresas em torno da criação de recursos que explicam o acumulo de capacidades inovadoras. De Figueiredo $(2000 ; 2004 ; 2013)$ nota-se que o processo de aprendizado envolve diversas formas que permite à empresa acumular competência tecnológica as quais, paulatinamente, podem ampliar sua capacidade de gerar e gerir a mudança técnica.

Mesmo que as particularidades sejam um dos objetos mais caros à perspectiva neoschumpeteria, uma generalização comum e decisiva a esse artigo é a de que a maioria das firmas inseridas em países de industrialização tardia iniciam suas atividades 


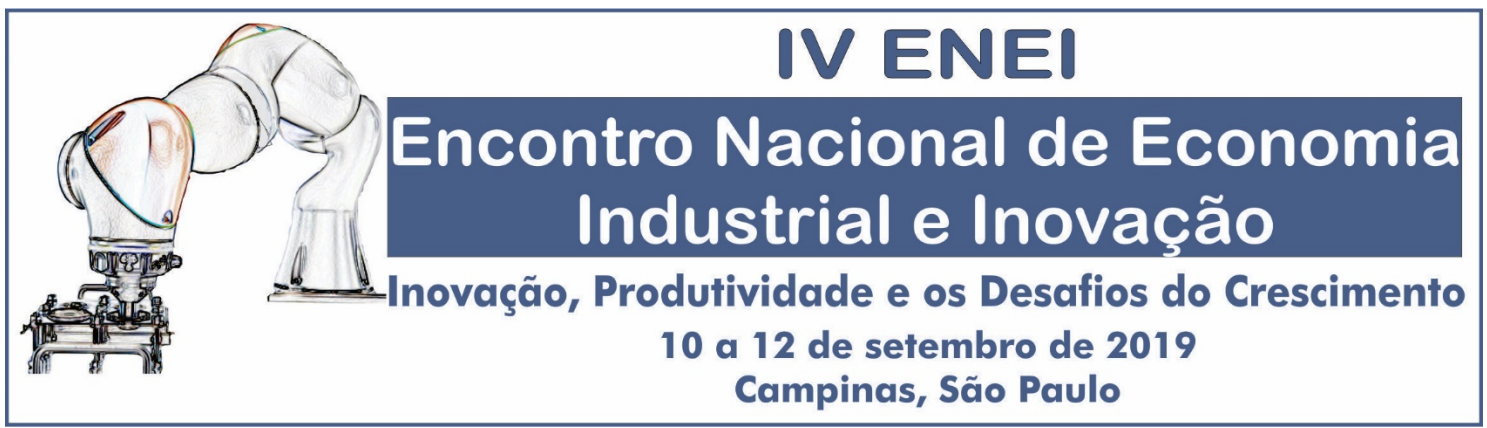

de produção com capacidades inferiores às inseridas nos países desenvolvidos, uma vez que elas não contribuem com as trajetórias iniciais das tecnologias que utilizam. $\mathrm{Na}$ realidade, isso ajuda a explicar debilidades do sistema de inovação em que estão inseridas, tais como a falta de universidades e centros de P\&D de ponta, além de outros serviços como os de metrologia e mesmo escolas técnicas e profissionais e centros de treinamento de nível adequado à mudança tecnológica no estado da arte (Figueiredo, 2013).

Daí que seja conveniente levar em consideração esse nível restrito de capacidades inicialmente, considerando-se a redução do hiato como seu problema essencial. E que, as vitórias nesse processo podem estar ligadas a outras variáveis de desempenho, tais como a financeira (Pinheiro et. al., 2017), e de exportações (Kim, 1980). Tal conveniência também é defendida por Ariffin, (2010) ao lembrar que:...for firms in late industrialising countries which usually start operations without even sufficient basic levels of technological capability, using these conventional proxy indicators would not measure whether firms have increasingly built-up higher capability levels (ARIFFIN, 2010, p. 354).

A investigação apresentada nesse artigo destaca a relação entre processo de construção e acúmulo de capacidades tecnológicas e a diversificação industrial que aumenta a complexidade econômica, o que levanta a necessidade de explorar os conceitos de diversificação e de complexidade, relacionando-os ao de acúmulo de capacidades tecnológicas.

No que se refere ao acúmulo de capacidades tecnológicas as pesquisas de Lall (1992), Bell e Pavitt (1995) e Ariffin e Figueiredo (2003) permitem identificar níveis, 


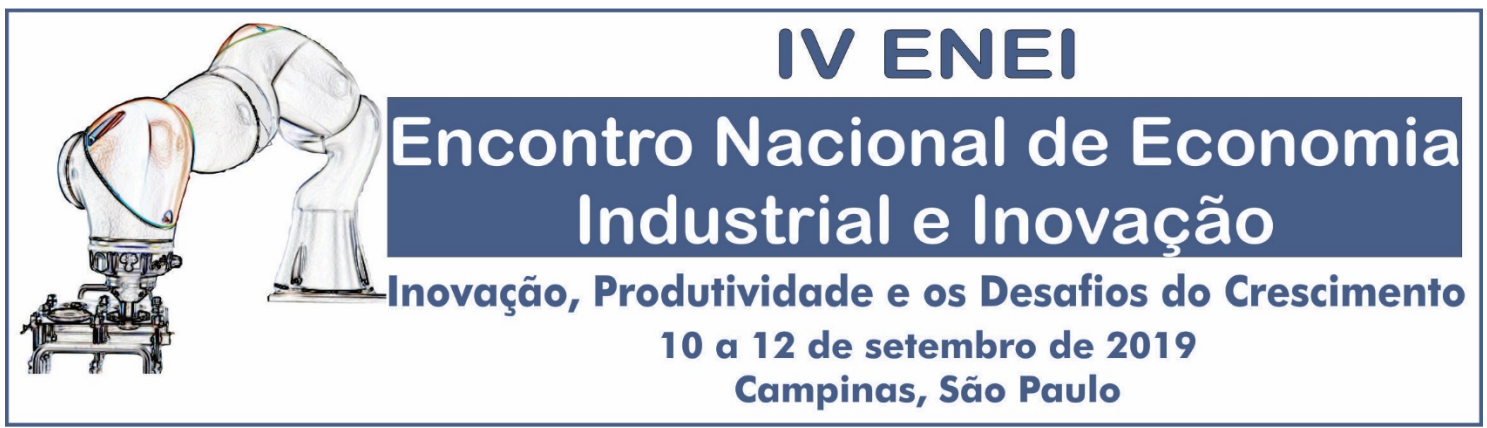

algo próximo a estágios de acúmulo dessas capacidades, o que representa apoio conveniente à pesquisa empírica em empresas de países em desenvolvimento.

Contudo, ainda que as empresas latecomers iniciem seus processos atrasados em relação às de desenvolvidos, há heterogeneidade também entre elas. Para Matheus (2002) a heterogeneidade na maneira como os recursos são empregados está relacionada às estratégias da firma em cada momento. Nesse sentido, Freeman e Soete (2008), mostraram como podem ser importantes as diferentes estratégias empresariais para definir o desenvolvimento não apenas delas mesmas, mas também de regiões e até países. Daí deriva-se a relevância da compreensão das trajetórias de acúmulo tecnológico de empresa latecomer a qual, para realizar o processo de catching up, precisa se engajar em um contínuo e sistemático processo de aprendizagem tecnológica, o que, envolve um importante componente de intencionalidade que pode se cristaliza em uma estratégia.

\subsection{DIVERSIFICAÇÃO COMO CONSEQUENCIA DO ACÚMULO DE}

CAPACIDADES: As contribuições seminais e complementares de Edith Penrose e David Teece

Para esse estudo, adotou-se como diversificação, o tradicional conceito de Edith Penrose (1959), mas o fundamento para o processo, foi complementado por contribuição de David Teece ${ }^{3}$. Importante ressaltar que há diferenças nas considerações

\footnotetext{
${ }^{3}$ É notável também a aproximação da perspectiva penrosiana com a schumpetriana sobre a firma. Penrose (1959), entendia a firma como uma fonte de recursos, cuja utilização seria organizada no quadro de uma estrutura administrativa. Para a autora, a fabricação de seus produtos em qualquer momento seria fruto da
} 


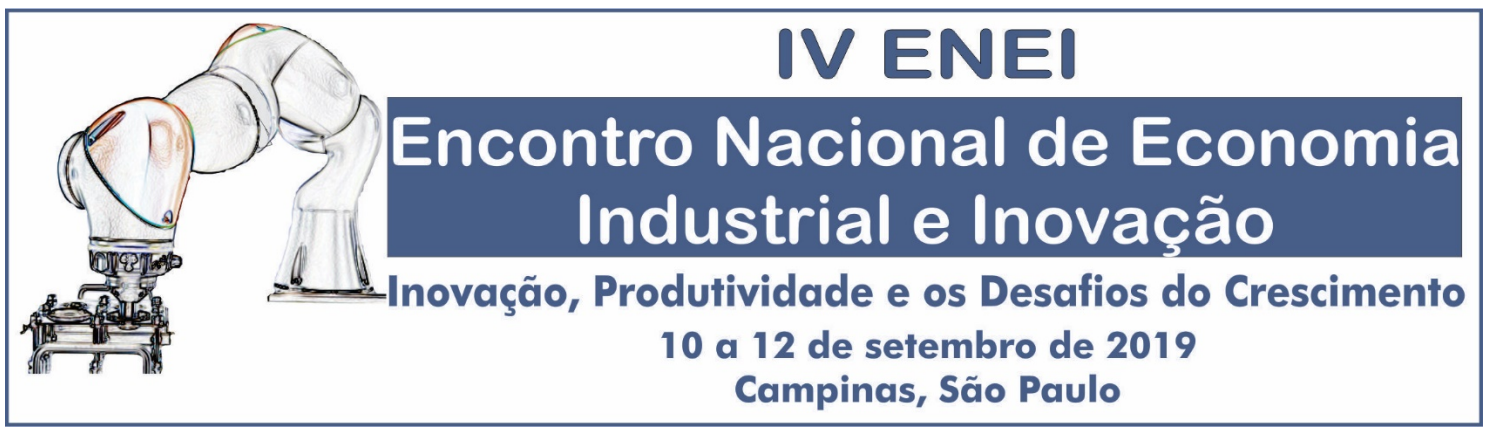

dos dois autores sobre o que é diversificação. Em Penrose o critério recaí sobre a produção, enquanto que em Tecce, o mercado é o critério relevante.

Para Penrose (1959) uma a firma diversifica sempre que, sem abandonar completamente suas antigas linhas de produtos, parte para a fabricação de outros produtos, inclusive produtos intermediários, suficientemente diversos daqueles que ela já fabricava, e cuja produção implique diferenças significativas nos programas de produção e/ou de distribuição. Já o conceito de diversificação adotado por Teece (1980;1982) diminui a distância entre diversificação e diferenciação, ao descrevê-la como um aumento na heterogeneidade da produção do ponto de vista do número de mercados supridos por esta produção. Assim, o conceito de Tecce (1980;1982), abre espaço para que a diversificação ocorra em cima de uma mesma linha de produção, o que seria apenas uma diferenciação para Penrose.

Desta forma, é provável uma diversificação em Teece possa ser uma diferenciação para Penrose. No entanto, dificilmente uma diversificação penrosiana seria uma diferenciação para Teece. Isso explica nossa opção por adotar o conceito penrosiano para a investigação empírica da diversificação, ao mesmo tempo em que utilizamos os avanços de David Teece sobre uma das causas do processo, particularmente as formas de economias de escopo.

\footnotetext{
"base de conhecimento" única, cristalizada nesses recursos. Na lógica da autora, as particularidades das firmas definem uma estrutura complexa orientada para o crescimento, distantes das estruturas cuja funcionalidade estaria restrita a definição de preços e quantidades. Tal afastamento da teoria neoclássica também está alinhado à perspectiva evolucionária da mudança econômica. de equilíbrio (BRITTO, 2002). Conforme Montgomery (1994, p. 167) descreve "...the resource view...differs from orthodox economic theory in two important respects: first, it focuses on heterogeneous, not homogeneous, firms; and, second, it is a theory of growth, not equilibrium.
} 


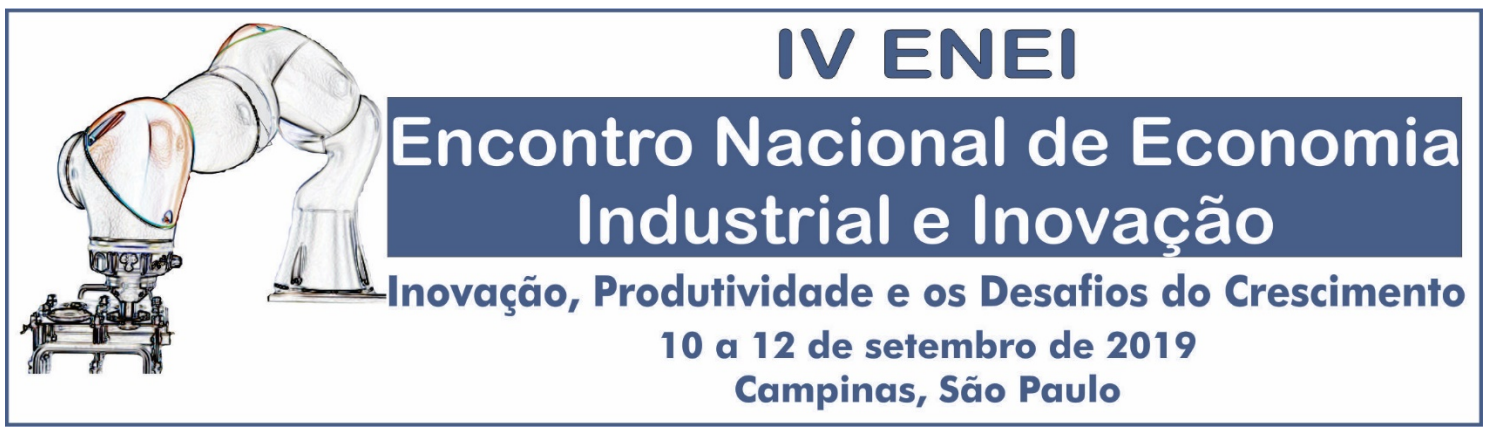

A ampla e detalhada contribuição de Edith Penrose sobre o crescimento da firma é ainda referência fundamental à compreensão do fenômeno. No que se refere a diversificação, alguns elementos merecem ser destacados. $O$ primeiro deles a intencionalidade. Segundo Penrose, o desejo de diversificar antecede a percepção da oportunidade (Penrose, 1959). Contudo, essa intencionalidade encontra limites nos recursos disponíveis, entre eles os "intelegíveis", relacionados não apenas às capacidades técnicas, mas também as administrativas, que, para a autora, poderiam ser de longe os mais importantes.

Outro elemento eram os custos de transação ${ }^{4}$, como se nota de sua referência ao uso parcial de certos recursos:

Even though a firm may not need a full-time salesman, engineer, or 'trouble shooter', it is often impossible, or at best difficult and disproportionately expensive, to acquire a part-time one, and for a given scale of operations it may be preferable to acquire a resource and use it only partly than to do without it (1959, p. 69).

A importância dos recursos "intelegíveis" que eventualmente são sub-utilizados, avança em Teece $(1980 ; 1982)$ na incorporação do valor ao know-how. Esse tipo de conhecimento, de caráter altamente tácito, cumulativo e derivado do learning-by-doing,

\footnotetext{
${ }^{4}$ Foi Coase quem primeiro trouxe à tona as questões relacionadas à existência dos custos de transação para o centro da discussão econômica. Coase $(1937$; 1960) explica que, nas operações de mercado, saber quem são os envolvidos, informar os termos com os quais se pretende conduzir uma negociação (ou seja, as cláusulas contratuais), e realizar o controle necessário para garantir que os termos do contrato sejam respeitados, são operações geralmente muito dispendiosas. Em função dos custos de transação envolvidos, muitas destas negociações nem chegam a ser realizadas.
} 


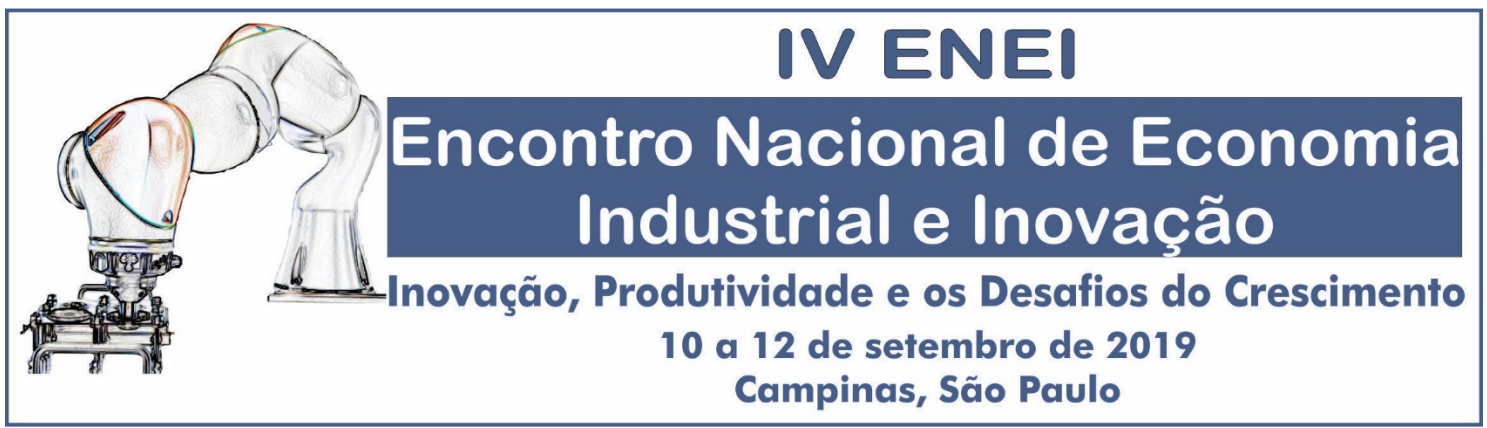

não poderia ser facialmente "adquirido" no mercado, sobretudo por impedimentos organizacionais e estratégicos 5 .

Nesse sentido, uma vez que a transferência do know-how inter-firma tem custos de transação consideráveis, para Teece $(1980,1982)$, a transferência de informações confidenciais ou conhecimento tácitos para atividades alternativas intra-firma é suscetível de gerar economias de escopo, se a empresa puder aprender métodos organizacionais que permitam realizar tal transferência a baixo custo.

Para efeitos do processo de diversificação Teece (1980) considera que a possibilidade de aproveitamento de economias de escopo estaria ligada a dois elementos essenciais: (i) se a produção de dois ou mais produtos dependem da mesma base de know-how e se é necessária uma troca recorrente e (ii) se um ativo indivisível e específico $^{6}$ é um insumo comum na produção de dois ou mais produtos.

O aspecto central do raciocínio é que a sub-utilização e a indivisibilidade advém das imperfeições de mercado causadas pelos custos de transação, que não permitem a expansão dos recursos da firma na exata medida em que ela precisa (como a contratação de um engenheiro por tempo integral, mesmo precisando-se de apenas por dois dias de

\footnotetext{
${ }^{5}$ Amit e Schoemaker (1993) descrevem que alguns recursos da firma, em especial às capacidades, estão sujeitas a falhas de mercado. Isso porque as capacidades implementam recursos que geralmente combinam e consubstanciam processos explícitos e elementos tácitos (tais como know-how e liderança) incorporados nos processos. Formam um conjunto de recursos e capacidades difíceis de negociar e imitar, escassos, apropriados e especializados que conferem a firma vantagens comparativas. Estes ativos tornam-se os determinantes intrínsecos que a firma possui e precedem e incorrem em lucro econômico, advindas de bem sucedidas estratégias competitivas da empresa.

${ }^{6}$ Teece (1980) destacou que a indivisibilidade associada ao know-how apresenta forte caráter learning-bydoing e de conhecimento tácito. No caso da WEG, como veremos a seguir, ela decorre, por exemplo, dos conhecimentos acumulados por funcionários para fazer ferramentas para diferentes geometrias de chapas, as quais por serem utilizadas em uma mesma prensa podem gerar diferentes carcaças de geradores elétricos (produto).
} 


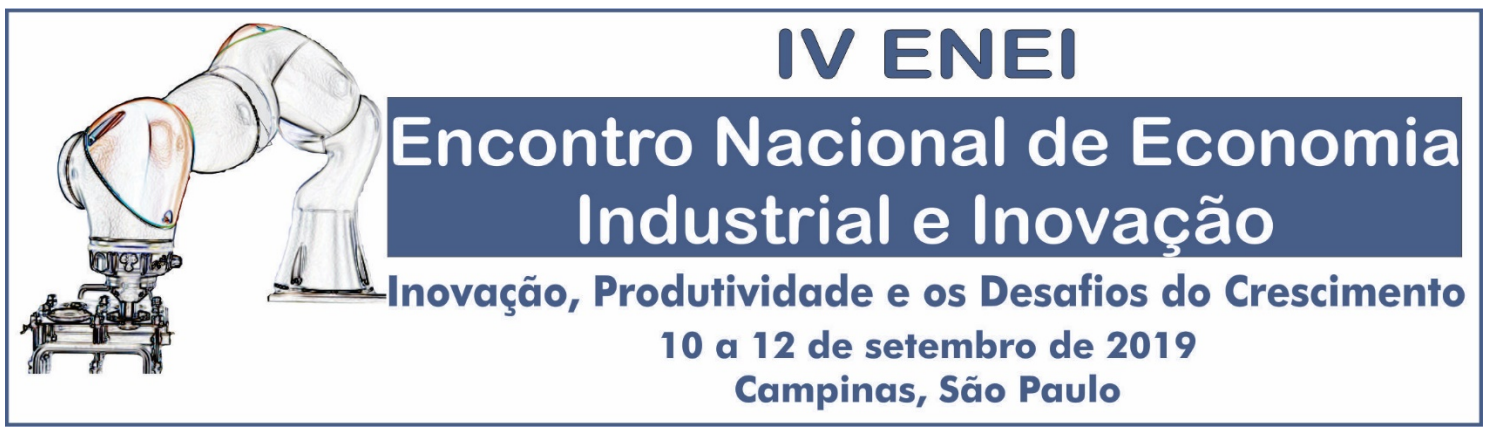

trabalho. Além do nível de incerteza que a disponibilização desse ativo ao mercado pode gerar, à medida que seu conhecimento pode ser "passado" a concorrentes que possam contratá-lo. Assim, haverá sempre recursos sub-utilizados que ajudam a explicar os caminhos da diversificação à medida que geram economias de escopo para a produção do produto da nova base produtiva.

Assim, a diversificação seria acompanhada por uma ampliação e/ou reorganização dos recursos da firma via transferência de know-how, sempre que puder aprender métodos organizacionais que permitam realizar a transferência a baixo custo, para atividades alternativas/complementares, aproveitando-se assim de economia de escopo dinâmica. Esse tipo de economia de escopo é dinâmica porque emerge de capacidade acumulada na trajetória da firma.

\subsection{IMPORTA A DIVERSIFICAÇÃO QUE AUMENTA A COMPLEXIDADE.}

Talvez a novidade empírica de maior potencial à análise econômica global contemporânea seja a "complexidade econômica", identificada segundo o grau de sofisticação produtiva de cada um dos produtos transacionados no comércio internacional. A definição desse grau de sofisticação baseia-se no grau de ubiquidade combinada ao de diversidade de produtos encontrada na pauta exportadora do país. A produção de bens não ubíquos supõe capacidade específica, pouco encontrada no resto do mundo, excluindo-se aqui bens altamente escassos na natureza, como diamante. Daí a necessidade de observar a diversidade de produtos que o país exporta. Assim, a não 


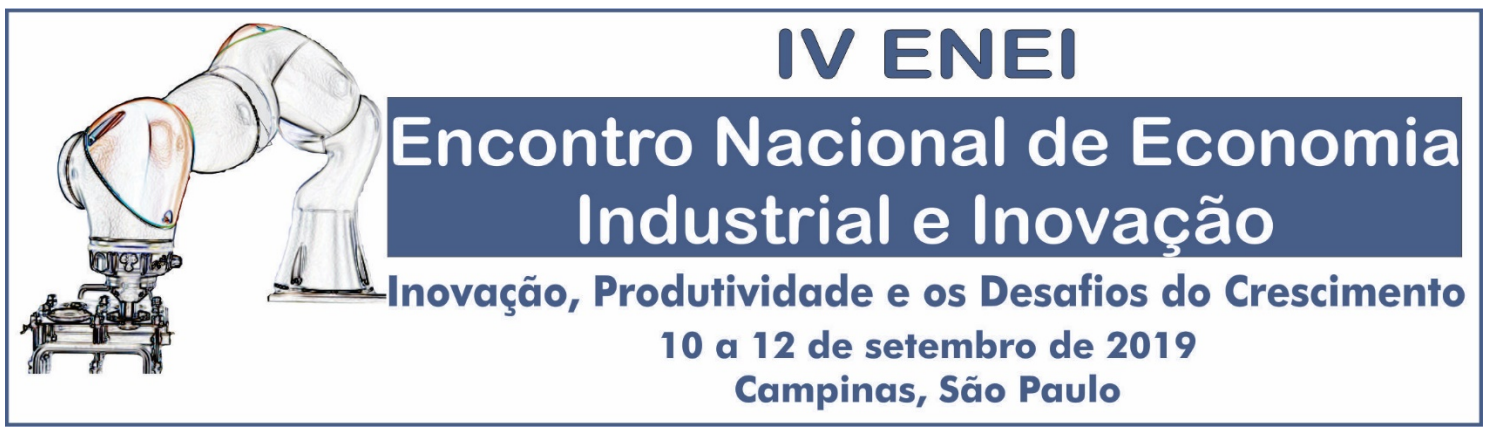

ubiquidade sem diversidade significa baixo grau de complexidade econômica de um país, ao passo que não ubiquidade e diversidade significa alta complexidade.

Disso deriva-se o índice de complexidade econômica (ICE), indicador que revelou forte potencial para correlação com variáveis de desempenho econômico como o nível de renda per capita. Para Hidalgo et. al. (2007), a discussão sobre a performance econômica dos países, perpassa os fatores produtivos básicos que são relativamente específicos para um mesmo conjunto de produtos. Os autores propõem que existe uma certa proximidade nos tipos de habilidades requeridas para a produção desse certo conjunto de produtos. Por isso, países especializados em um produto podem ou não se especializar em outro. Nesse sentido afirmam que a alteração no padrão de especialização verificada em na história dos países ocorreu, preferencialmente, para bens relacionados ou próximos. Hausmann e Klinger (2007), defenderam que as mudanças nas vantagens comparativas reveladas das nações ocorrem principalmente devido ao padrão de parentesco dos produtos. Os países tendem a evoluir sua produção exportadora passando dos produtos atuais para produtos "próximos".

A causa dos diferenciados níveis de complexidade econômica revelada pelas pautas exportadoras dos países, remete, segundo os autores, ao acúmulo pregresso de capacidades de produzir. Essas são tratadas de forma relativamente genérica, relacionadas aos direitos de propriedade, regulação, infraestrutura e competências laborais (incluindo conhecimento tácito). Nesse sentido, a perspectiva da complexidade ainda apresenta debilidade por não estabelecer uma conexão teórica ou mesmo empírica entre construção de capacidades e complexidade. 


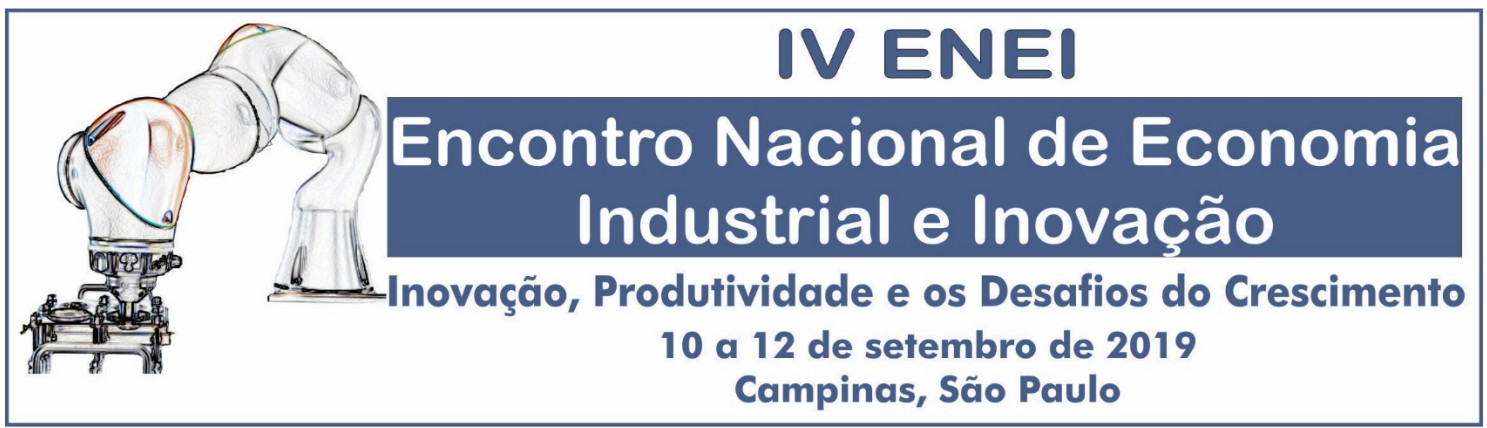

Talvez o melhor avanço teórico esteja em Nubler (2014) que procurou relacionar seu conceito dinâmico de cathing up com as capacidades (capabilities) específicas e não facialmente transferíveis dos países. Tais capacidades seriam expressas em opções para a mudança estrutural e tecnológica, sendo que, o "the concept of options [...] implies that capabilities are preconditions for productive transformation and that the development of capabilities needs to precede transformation of productive structures and technological upgrading" (Nubler, p. 121, 2004).

Nesse sentido, como veremos a seguir, no caso da WEG o cathing up da firma foi estabelecido por meio de esforços contínuos de aprendizagem voltados à dominar a dinâmica da inovação dos segmentos em que atuava. As capacidades de inovação acumuladas (de forma precedente) em níveis relativamente altos lhes deram a opção (Nubler, 2014) de realizar a mudança estrutural em sua esfera de atuação. Assim o artigo avança sob essa linha de pesquisa sugerindo, por meio de evidência empírica, que a construção de capacidades tecnológicas está relacionada ao aumento da complexidade produtiva, notadamente quando tal capacidade de inovar já alcançou certo grau.

Como mostra a Figura 1, a investigação empírica que sustenta a argumentação desse artigo, foi realizada sobre duas diversificações que aumentaram a complexidade produtiva da WEG. Os níveis dados pelo Product Complexity Index - PCI seguem a classificação do comércio internacional com código de 4 dígitos de desagregação SITC- $4^{7}$.

\footnotetext{
${ }^{7}$ Cabe ressaltar que embora tanto a SITC 7162 quanto SITC 7161 tratem de classificações para ambos os produtos (motores e geradores elétricos), a WEG produziu e construiu capacidades tecnológicas primeiramente apenas em motores elétricos de corrente alternada, vindo a fazer um esforço de diversificação para a produção de geradores elétricos (especificamente geradores de corrente contínua)
} 

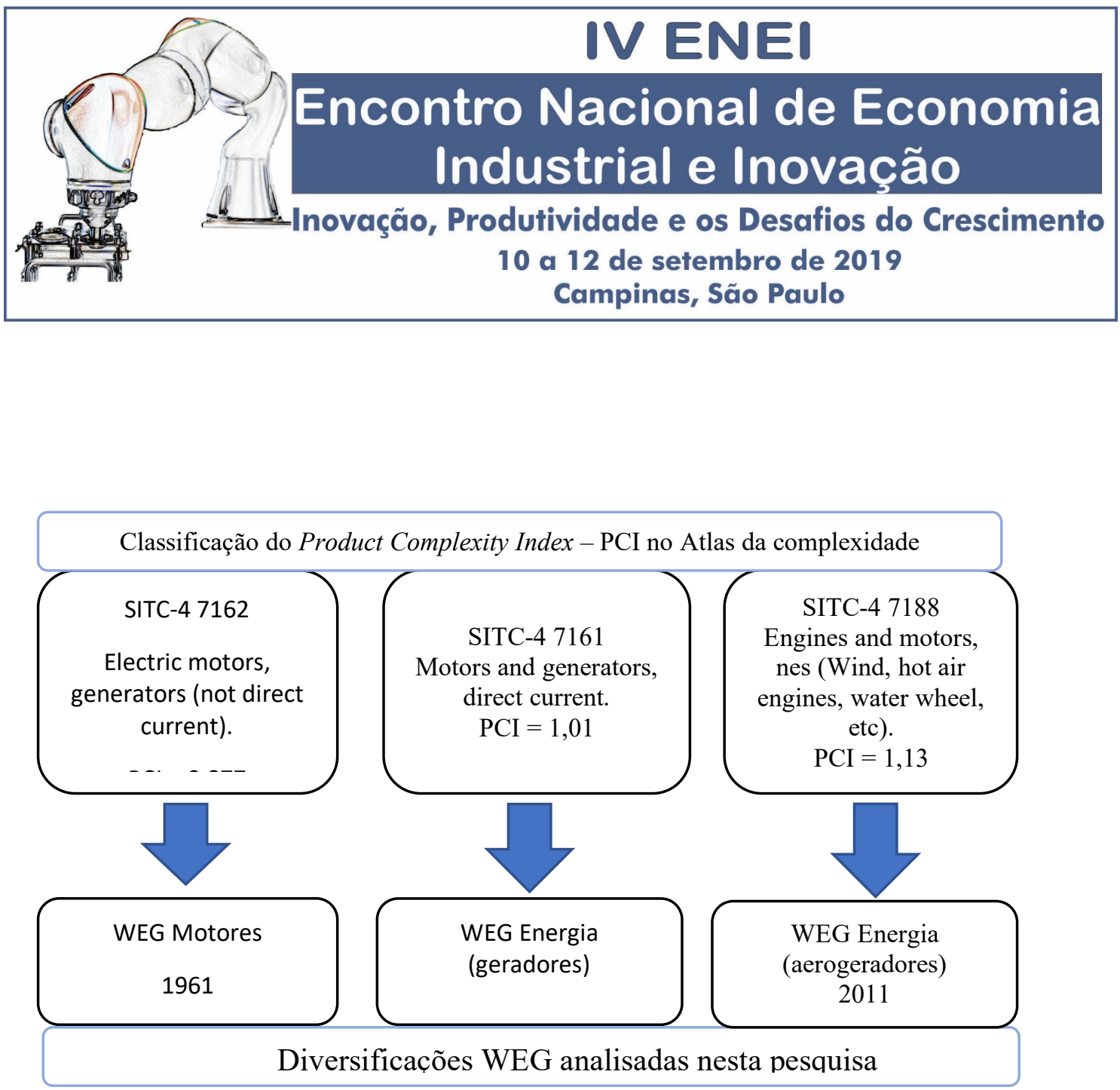

Figura 1 - Complexidade do produto segundo o atlas da complexidade para as diversificações analisadas nesta pesquisa.

Fonte: Elaboração própria.

Os dados apresentados na Figura 1 mostram que para motores e geradores de corrente alternada (SITC 7162) o índice de complexidade do produto é 0,877, para motores e geradores de corrente contínua (SITC 7161) o índice é 1,01, e para aerogeradores o PCI é 1,13. Desta forma, os dados do PCI apontam que a diversificação de motores elétricos para geradores elétricos e de geradores elétricos para aerogeradores ocorreram em termos de bases produtivas mais complexas.

somente em 1980. Desta forma, acredita-se que a utilização das nomenclaturas SITC 7162 e 7161 sejam uma proxy adequada. 


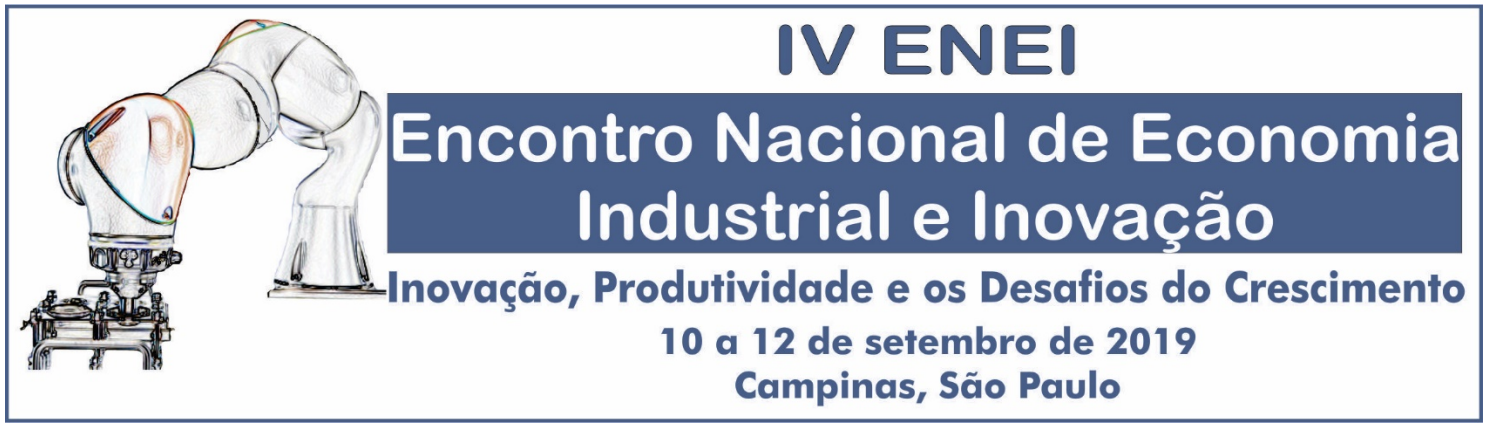

\subsection{NÍVEL DE CONSTRUÇÃO DE CAPACIDADES, KNOW-HOW, ECONOMIA DE ESCOPO E A DIVERSIFICAÇÃO QUE AUMENTA A COMPLEXIDADE.}

As três seções acima procuraram apresentar as referências conceituais centrais à investigação empírica que sustenta os resultados apresentados a seguir. Antes de irmos a eles, importante estabelecer as conexões conceituais que permitiram a elaboração da proposição à investigação.

A noção de que o know-how explica parcela da diversificação pela possibilidade de aproveitamento de economia de escopo, deixada por David Teece é insuficiente para elucidar sobre o nível dos conhecimentos administrativos e técnicos que tornariam possível a diversificação, especialmente se essa tiver caráter tecnologicamente sofisticado, tal como as que aumentam a complexidade produtiva. Por outro lado, as contribuições de Matin Bell, Norela Ariffin, Paulo Figueiredo entre outros, destacadas na primeira seção, dão conta de mostrar que há um caminho (ainda que não necessariamente seguindo a sequencia de etapas com exatidão) para o acúmulo de capacidades tecnológicas que, especialmente para empresas de inseridas em países em desenvolvimento, parte de nenhuma capacidade inovativa e evoluí de forma progressivamente ampliar sua capacidade de gerar e gerir a mudança tecnológica, ou seja, de avançar em sua capacidade de inovar.

Assim, considera-se que não se pode esperar uma diversificação que aumente a complexidade sem que um certo nível não incipiente de capacidade de gerar e gerir a mudança técnica esteja devidamente internalizada entre os recursos da firma. A 


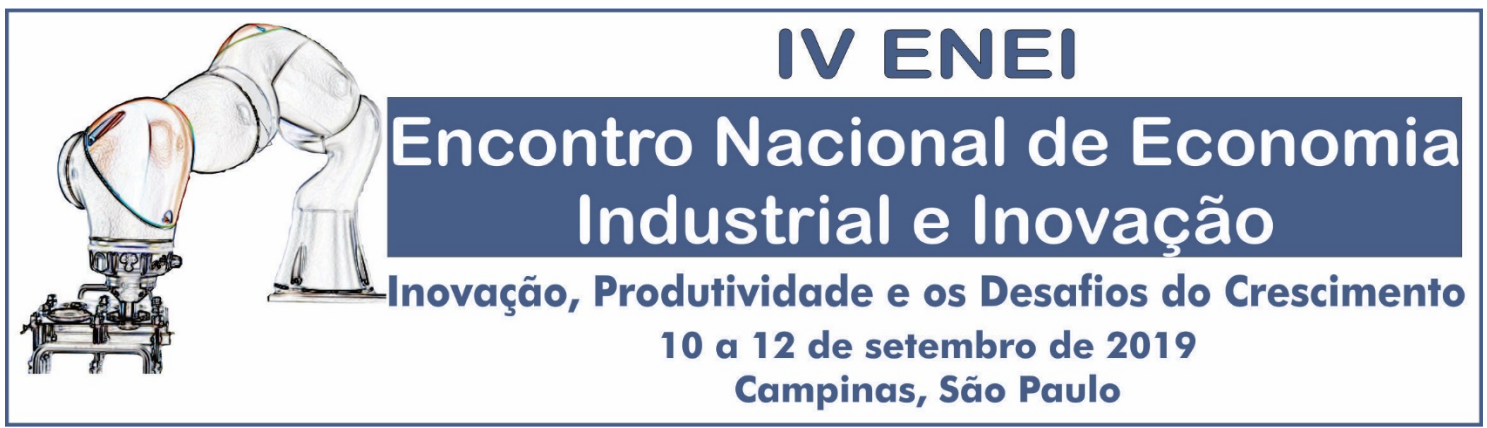

proposição é portanto a de que: $\mathrm{O}$ processo de diversificação que aumenta a complexidade é fruto de aproveitamento de economias de escopo que, nhoque se refre ao know how, derivada de estratégia tecnológica agressiva, capaz de acumular capacidade de inovação em nível não incipiente, o que informa à empresa que ela não parte do zero para enfrentar a competição em torno da dinâmica da inovação do novo produto.

\section{PROCEDIMENTOS METODOLÓGICOS}

A pesquisa é um estudo de caso, que utilizou-se de informações primárias e secundárias. Foram realizadas 36 entrevistas em diversas oportunidades com professores familiarizados com estudos de caso sobre uma pesquisa de níveis em capacidades tecnológicas, profissionais, técnicos, e consultores da empresa (bem como visitas realizadas ao Museu WEG, e visitas técnicas supervisionadas a WEG Motores e a ferramentaria) além de técnicos em eletrotécnica e professores da engenharia civil da universidade (UFSC) de laboratórios que apoiam o desenvolvimento tecnológico da empresa a anos, totalizando 2.340 minutos de gravações, ou seja, 39 horas ${ }^{8}$.

O primeiro procedimento consistiu em uma investigação sobre momentos da diversificação da WEG. Foram utilizados dados secundários, a partir do site do atlas da complexidade econômica ${ }^{9}$, que disponibiliza os dados do comércio internacional na forma de redes de ligações do espaço-produto. Especificamente, utilizou-se dados do comércio internacional com código de 4 dígitos de desagregação (SITC-4), para analisar se a

\footnotetext{
${ }^{8}$ Importante mencionar entrevista com Moacyr Sens (3 horas), primeiro engenheiro da empresa e que ainda atua como consultor sênior.

${ }^{9} \mathrm{http}: / /$ atlas.cid.harvard.edu/
} 


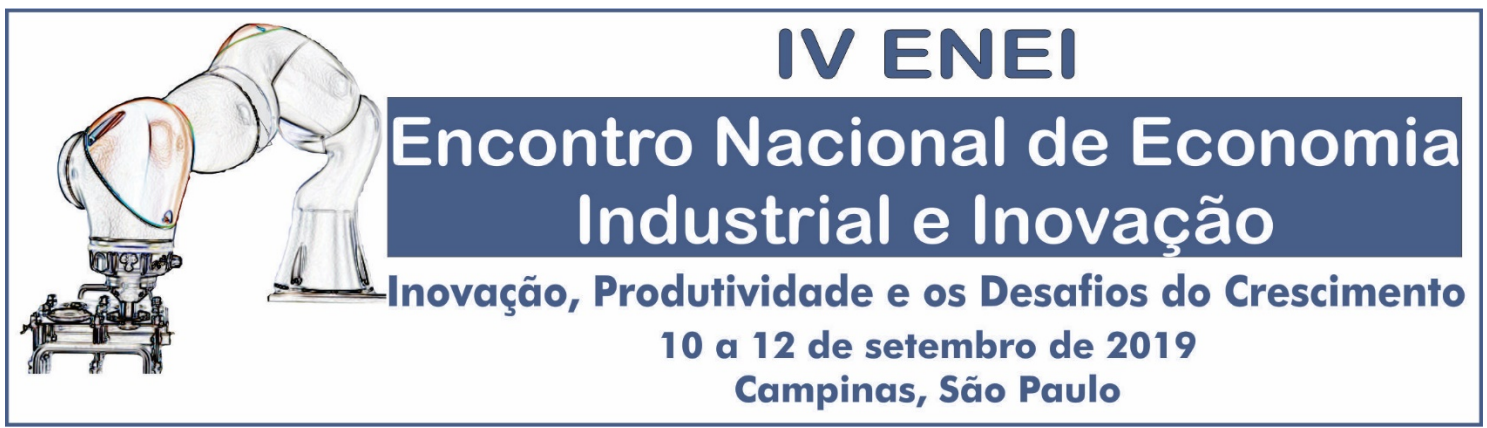

formação da WEG para as bases produtivas em motores elétricos, geradores e aerogeradores constituíram diversificações para bases produtivas mais complexas.

A investigação sobre eventos de diversificação ao estilo Penrose foi realizada junto a funcionários da empresa, mas também em loco, pelo primeiro autor desse artigo, em visita guiada.

Para a realização da pesquisa de campo no que tange o preenchimento dos níveis de capacidade tecnológica apresentado no Quadro 1 (em anexo), a investigação foi conduzida tendo como base as recomendações da linha de pesquisa sobre processo de acúmulo de capacidades tecnológicas em firmas latecomers (Lall, 1992; Bell e Pavitt, 1995; e Ariffin e Figueiredo 2003), que enfatizam a importância de uma maior desagregação de níveis de capacidades tecnológicas para pesquisas empíricas em empresas latecomers. Neste sentido, optou-se por uma desagregação em 6 níveis, sendo um de capacidade produtiva e 5 de capacidade inovativa, tal como descrita em Figueiredo (2013). O foco esteve limitado à capacidades técnicas, ou seja, não foram exploradas as organizacionais, pelos limites da formação dos autores do artigo.

A Figura 2 mostra o modelo de referência para cumprir a proposta de investigação. $\mathrm{O}$ foco pontilhado em azul destaca as três dimensões e suas relações, ou seja, (i) os mecanismos de aprendizagem que permitem o (ii) acúmulo de compacidades tecnológicas, os quais permitiram (iii) a diversificação produtiva da empresa, pela obtenção de economias de escopo à medida que as capacidades (ii) se elevam. 

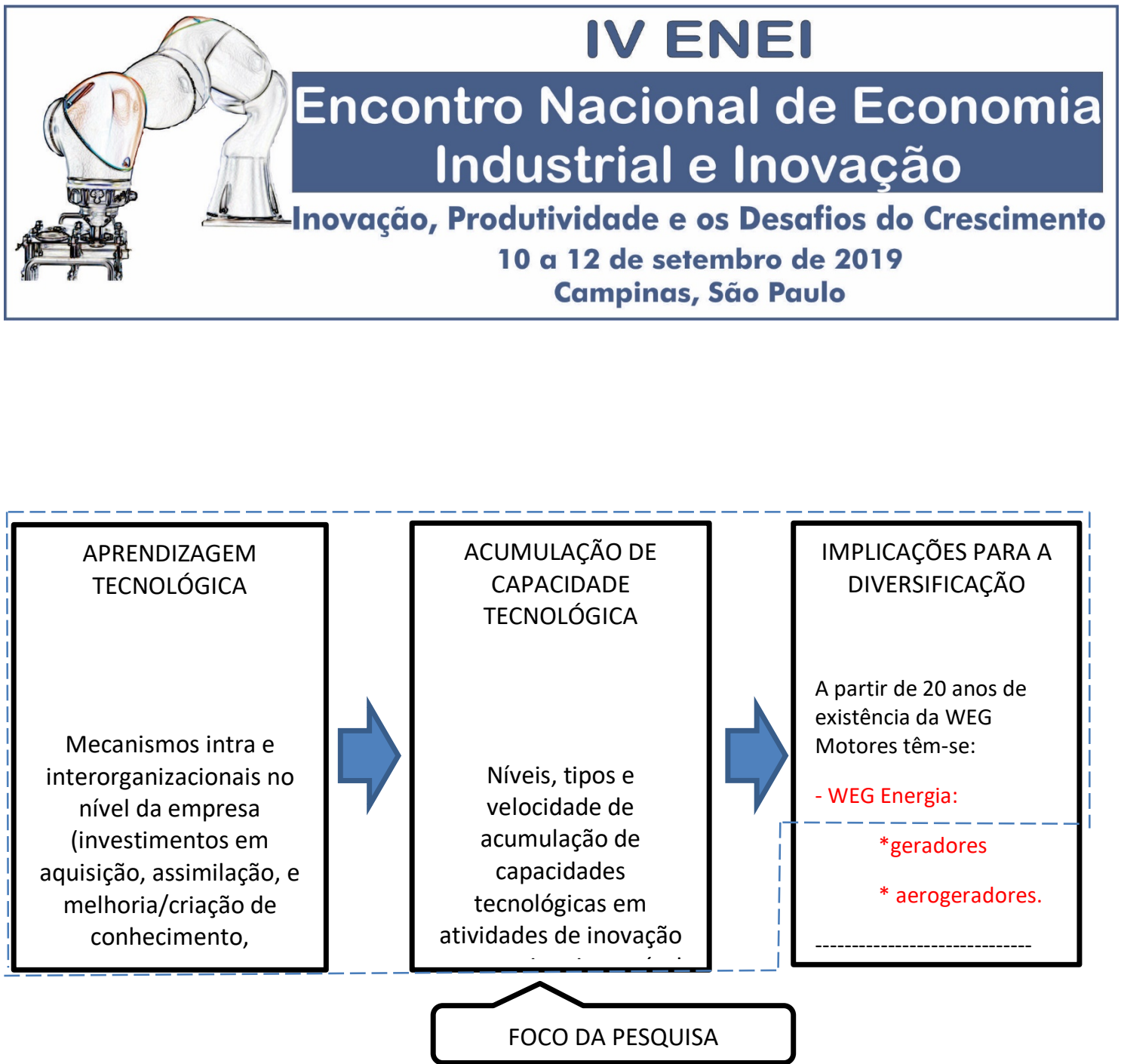

Figura 2 - Modelo analítico que prevalece na literatura para a acumulação de capacidades tecnológicas.

Fonte: Adaptado de Bell e Figueiredo (2012, p. 19).

\section{A CONSTRUÇÃO DE COMPETÊNCIAS COMO MOTIVO DE DIVERSIFICAÇÃO QUE AUMENTOU A COMPLEXIDADE PRODUTIVA NA WEG}

Esta seção está sub dividida em duas, cada uma delas trata dos esforços realizadas em uma base produtiva e que contribuíram para diversificação que aumentou a complexidade. A primeira trata dos esforços de aprendizagem e do processo de acúmulo de capacidades tecnológicas na produção de motores elétricos que apoiaram a diversificação para geradores elétricos da WEG. A segunda seção faz o mesmo para geradores e a diversificação para aerogeradores. A base são os frameworks de Lall (1992), Bell e Pavitt (1995) e Ariffin e Figueiredo (2003) e os exemplos de Figueiredo 


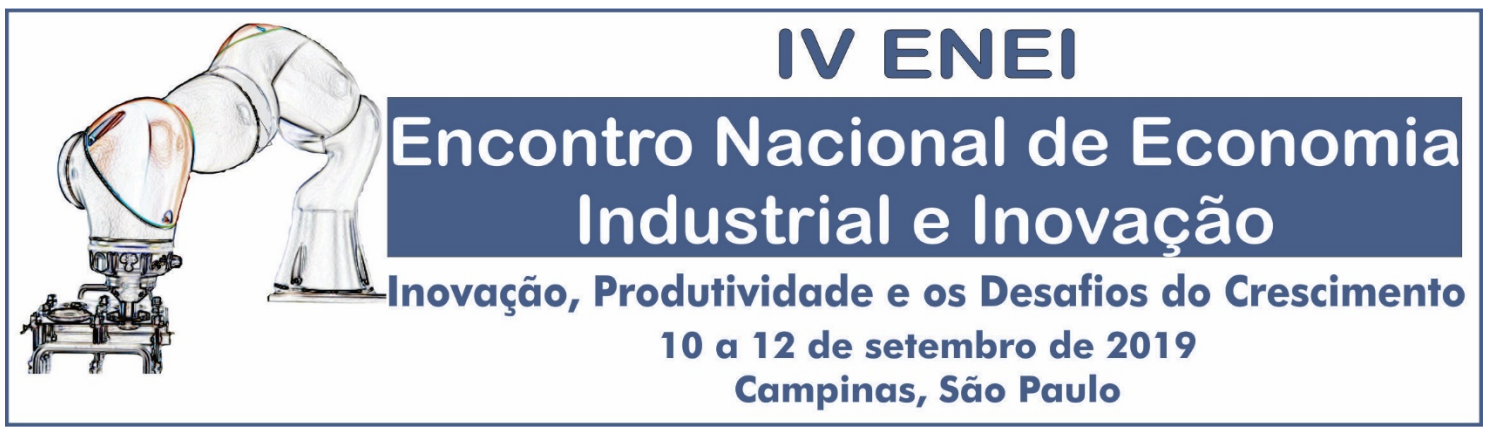

(2013). As seções subseções iniciais mostram como os esforços de aprendizado refletem agressividade tecnológica em busca da capacidade de gerar e gerir a mudança técnica, enquanto que as seçõe sobre acúmulo de capacidades mostram como e quando a WEG adquiriu o nível não incipiente de capacidade tenológica que lhe permitiu realizar a diversificação, sempre destacando porque essas capacidades foram convenientes.

4.1. Da Produção de Motores para a Produção de Geradores.

4.1.1. Os Mecanismos de Aprendizagem para o acúmulo de capacidades em motores elétricos

Esta seção apresenta cronologicamente os mecanismos internos e externos de aprendizagem utilizados pela WEG em seu processo de construção de suas capacidades tecnológicas em motores elétricos, que antecedem a diversificação para geradores elétricos. Pode-se notar complementaridade entre os mecanismos internos e externos, mas principalmente um nível significativo de agressividade da empresa em torno do aparente objetivo de dominar a dinâmica da tecnologia, ou, em outras palavras, ampliar a capacidade de gerar e gerir a mudança tecnológica.

Antes de discutir tais mecanismos é importante ter em mente que na época de sua fundação a WEG estava imersa em um ambiente relativamente hostil à sua expansão. A mão de obra não era especializada, na longínqua Jaraguá do Sul da década de 1960 do século passado. A demanda maior para motores elétricos, já estava atendida por empresas estrangeiras, restritas a longínqua São Paulo para onde os muitos 


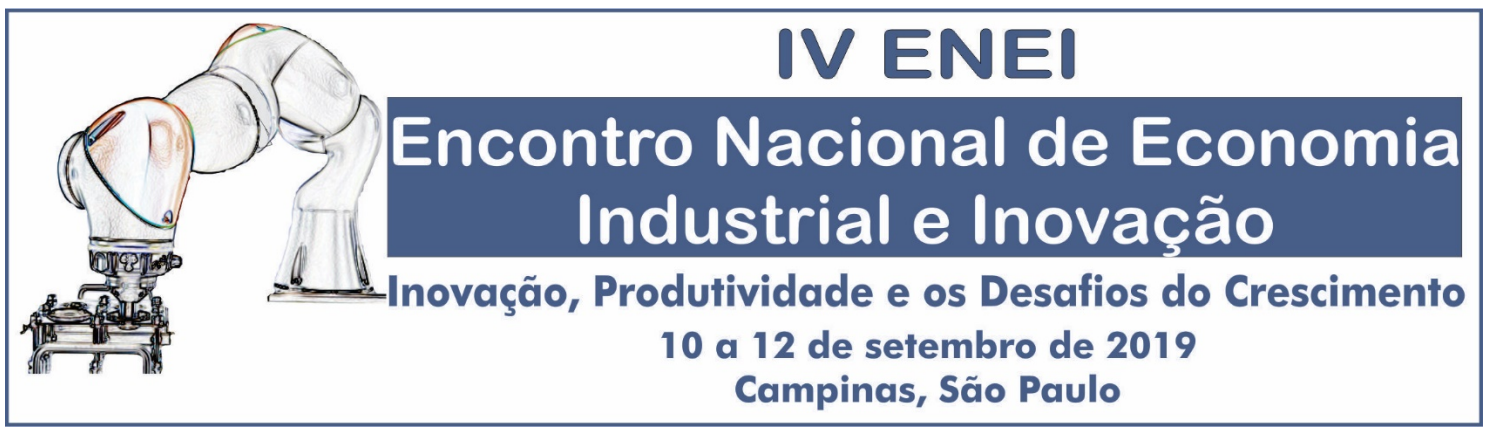

quilômetros de distância teriam de ser percorridos, à época, parcialmente por estrada e chão. As dificuldades podem ser traduzidas também no fato de que um contato telefônico com um potencial demandante poderia demorar três dias. Além disso, a mão de obra local estava voltada a atividade rural (TERNES, 1986).

Desse contexto, um interessante aspecto do processo de aprendizagem merece destaque. Houve desde o início um sistemático esforço para codificação e socialização interna do conhecimento adquirido com fontes externas. Embrião das rotinas de codificação dos conhecimentos podem ser encontrados já nessa época. Os usos desses mecanismos são complementados por outros, considerados avançados inclusive para empresas da atualidade, tais como a formação e operacionalização de um Centro de Treinamento interno, assim como, de programas de qualidade no produto e no processo. À medida que as formas de aprender externamente são internalizadas, por exemplo, pelo centro de treinamento, a firma passa a diversificar as fontes externas de conhecimento.

Ainda que os detalhes estejam melhor documentados em autor (2018), cabe uma breve síntese. Desses eventos, destaca-se inicialmente a realização de uma viagem à Alemanha em 1968 pelos membros fundadores, o que gerou contrato com o escritório de projetos do Dr. Ing Ernst Braun, referente a um novo pacote tecnológico ${ }^{10}$ sobre tecnologia de produção de motores. Nesta mesma visita, aproveitaram para observar in loco modelos de formação e qualificação de trabalhadores em firmas alemãs, ou seja, o que representava o estado da arte dos processos de organização da produção. Isso foi

10 Conforme a pesquisa de campo, as dificuldades em compreender a tecnologia dos processos de produção do motor Braun suscitou a necessidade da aquisição dos projetos dos processos de produção, os desenhos de suas máquinas, bem como a realização de treinamento com os fornecedores da tecnologia. Daí segue-se o envio contínuo de especialistas da empresa por toda a década de 1970 à Alemanha para ampliação da compreensão da dinâmica da inovação do artefato em questão. 


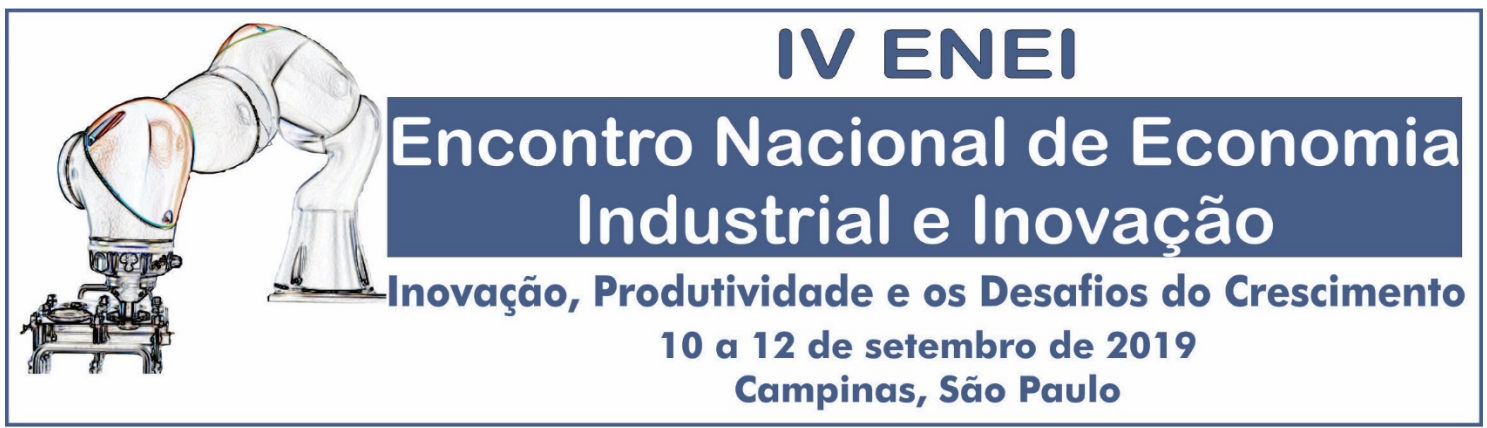

estímulo suficiente à edificação do Centro de Treinamento da WEG, inovação organizacional de altíssimo nível não apenas no contexto regional, mas também para o Sistema Nacional de Inovações brasileiro da época. O Centro, institucionalizara uma escola de treinamento para formação de nova mão-de-obra, mas também para o continuo aperfeiçoamento da mão-de-obra já existente (Ternes 1986; 1997). Segundo Moraes (2004), essa inovação organizacional deu à WEG a flexibilidade para planejar e formar toda a mão de obra necessária para seus avanços sub-sequentes, o que envolveu amplos programas de treinamento.

À medida que o aprendizado gerado era acumulado, passou-se a notar que a empresa incorria em significativos custos com a transmissão de certos conhecimentos entre os funcionários. Tal percepção ocorrera em 1978. Dela, fora institucionalizada a prática de codificar o máximo e conhecimentos técnicos possíveis, padronizando e fixando por escrito todos os sistemas de trabalho e as definições das competências e formas de atuar (TERNES, 1986; 1997; SCHMITZ, 2001; VIDIGAL, 2011).

Logo em seguida, outra grande inovação organizacional fora instituída pela criação do centro tecnológico WEG em 1980, já com o compromisso de desenvolver tecnologia próxima à fronteira, revelando que a empresa já focava em uma estratégia defensiva ou até ofensiva (Freeman e Soete, 2008), uma vez que, passou a contar com equipes próprias de pesquisadores e laboratórios sofisticados. Nesses, passaram a ser realizados ensaios e a fabricação de protótipos, além de preservar a documentação técnica de cada produto (TERNES, 1986; 1997; SCHMITZ, 2001; VIDIGAL, 2011).

Esses mecanismos explicam o acúmulo interno de capacidades, bases para a possibilidade de diversificação, o que procuramos apresentar a seguir. 


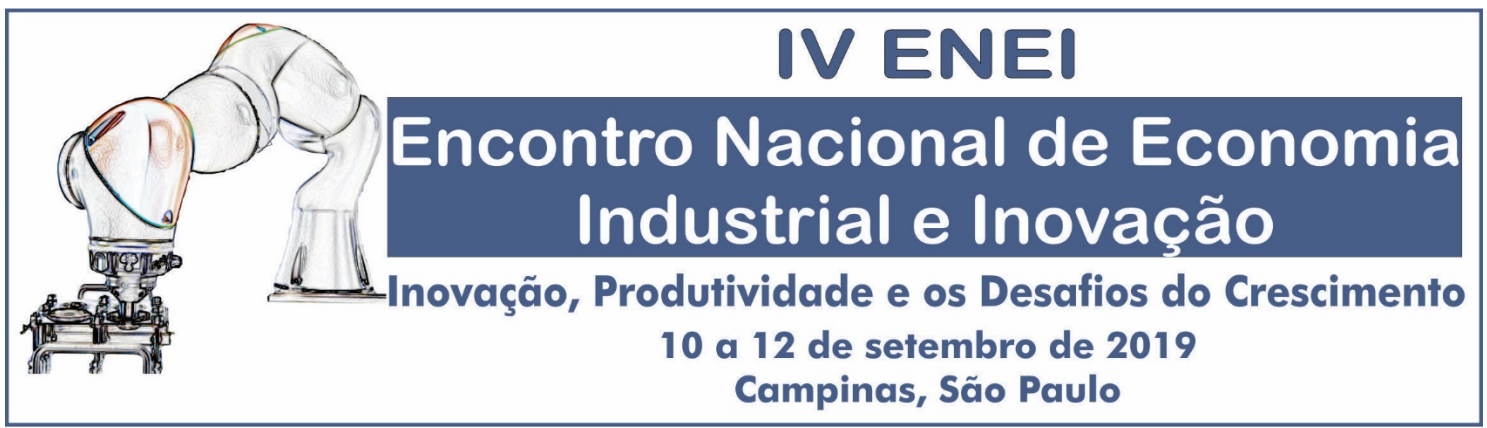

4.1.2 Acúmulo de capacidades tecnológicas em motores e a obtenção de economias de escopo que permitiram a diversificação para Geradores Elétricos

Essa seção apresenta o processo de acúmulo de capacidade tecnológica em motores elétricos e discute sua importância para a obtenção de economias de escopo que resultaram na diversificação produtiva de maior complexidade econômica, para geradores elétricos. São resultados resumidos da pesquisa, mais bem documentada em Nardo (2018). A necessidade de sintetizar fez com que se optasse por explorar apenas uma dimensão de capacidade tecnológica neste artigo, a de tecnologia de produto, mais especificamente, a eficiência energética em produtos e materiais, algo considerado decisivo entre os profissionais entrevistados. A síntese histórica desse processo basea-se na estrutura de níveis de capacidades tecnológicas aprsentada no Quadro 1, em anexo.

Historicamente, o ano de 1961 é entendido como o período em que aprender a produzir motores era a meta, ou seja, a meta é a capacidade básica de produção (Ariffin, 2010) e (Bell e Figueiredo, 2012).

Já as capacidades de inovação básica e incremental intermediária, foram adquiridas entre 1961 e 1969, mas não há precisão de quando passou-se de uma para outra. Tal inferência está alicerçada em dois fatos, verificados pela literatura e confirmados na pesquisa de campo: (i) a preocupação e realização de modificações com o objetivo de reduzir o uso de materiais, sem incorrer em perda de eficiência energética e combinada ao aumento da potência dos motores, e em (ii) 1970, a clareza de que a WEG já apresentava nível de capacidade tecnológica incremental avançada, como discutido logo a seguir. 


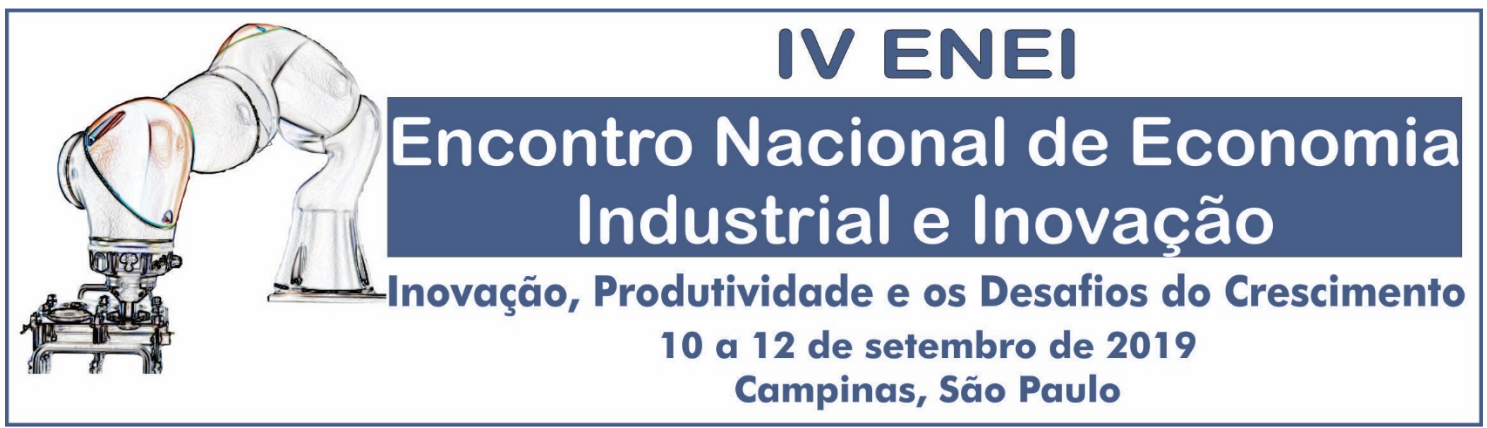

Ocorre que, em 1970 a empresa já produzia motor elétrico que se enquadrava na International Electrical Comission - IEC (BRASIL, DIEGUES E BLANC, 1995). Conforme Ternes $(1986$; 1997), concomitante a absorção e reprodução do novo modelo, que continha as especificações técnicas para motores elétricos nas potencias de 0,5 a 25 cavalo-vapor, a WEG desenvolveu, entre 1968 a 1970 motores elétricos de potência superior aos permitidos pela simples transferência do pacote tecnológico. Os novos motores tinham 30, 40 e $50 \mathrm{cvs,} \mathrm{o} \mathrm{que} \mathrm{significa} \mathrm{modificações} \mathrm{na} \mathrm{estrutura} \mathrm{física} \mathrm{do}$ produto e do processo, com ampliações significativas de dimensões, as quais somente foram possíveis por modificações substanciais em todo o produto e nas diversas etapas produtivas. Disso, deduz-se o nível de capacidade inovativa incremental avançada já acumulada pela WEG em produto. Não obstante, a pesquisa de campo revelou que as modificações necessárias no produto foram realizadas também por capacidade acumulada no desenvolvimento de ferramentas com designs específicos ao novo produto $^{11}$.

Essa breve descrição dos momentos de acúmulo de competência tecnológica da WEG em torno da capacidade de gerar e gerir a mudança técnica na dimensão do

11 As duas décadas seguintes são espaço de importantes inovações sofisticadas (avançadas), como melhoramentos no sistema de troca térmica, evolução dos materiais magnéticos, assim como nos isolantes empregados. Os modelos da década de 1990, por exemplo, baseavam-se em importante avanços do projeto mecânico e do campo eletromagnético, os quais implicaram significativa melhora da densidade de potência. Do avanço nesse sentido, a empresa passou a ser capaz de produzir um motor de maior potência com menor volume de massa, o que envolveu mudança na relação dos elementos básicos da mudança tecnológica, revelando nova elevação do nível de capacidade de gerar e gerir a mudança tecnológica nesse produto. Esse é o período em que a empresa alcançou o nível de capacidade arquitetural O maior exemplo, é o lançamento em 2010 do WMagnet, produto que demandou modificações tecnológicas, não somente pela melhora na densidade de potência, mas também nos elementos básicos envolvidos na tecnologia, ao substituir o uso dos enrolamentos de campo antes feitos por fios de cobre por imãs permanentes. 


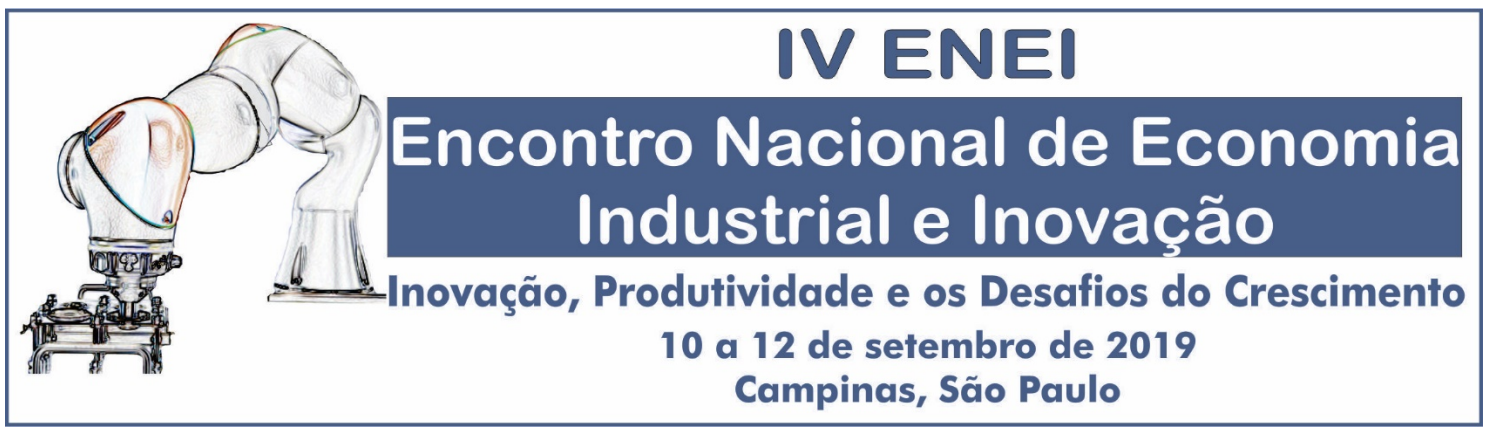

produto motores elétricos é importante porque representa um ativo intangível que permitiu vislumbrar menor risco na atividade de diversificação produtiva que aumentou a complexidade econômica, revelada posteriormente na nova base produtiva (geradores).

De fato, a pesquisa de campo mostrou que no momento da diversificação para a produção de geradores, em 1980, a infraestrutura industrial básica para produzir geradores já estava internalizada, tornando possível a obtenção de economias de escopo de capital, que representaram menor risco à diversificação que aumenta a complexidade. Entre as máquinas e equipamentos com dupla aplicação e que geravam a percepção de alta possibilidade de aproveitamento de economias de escopo de capital, estão a estamparia e a trefilação. Contudo, houve também para esses casos, economia de escopo de know-how, uma vez que os processos produtivos não são idênticos para produzir motores e geradores quando utilizam essas máquinas. Foi o know-how acumulado por trabalhadores da WEG nessas etapas que permitiu adaptações no uso dessas máquinas para a produção de geradores.

Nesse sentido, foi sempre citado como "muito importante" o fato de que em 1980 a empresa já contava com capacidade acumulada no desenvolvimento de ferramentas (derivada de setor de ferramentaria, iniciado já em 1968), que acopladas às máquinas de estamparia e trefilação permitiam as modificações e inovações de processo necessárias aos melhoramentos do projeto básico do gerador.

Adicional à essa capacidade em processo, foi também destacada a capacidade de realizar eventuais modificações nas características físicas do produto, as quais foram acumuladas no desenvolvimento de melhorias para os motores elétricos. Daí que 


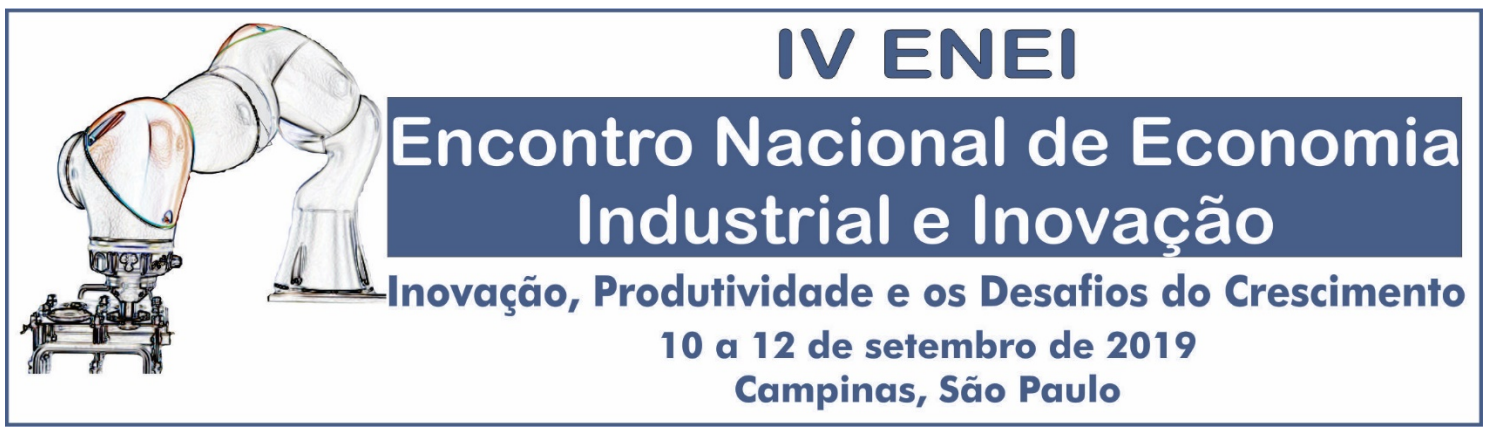

mudanças no projeto inicial da carcaça para produção de geradores tenham ocorrido desde os primeiros modelos ${ }^{12}$. Em outras palavras, as alterações no desenho da carcaça facilitavam o processo de fundição. $\mathrm{Na}$ verdade, inicialmente optou-se por adequar o produto novo (geradores) ao processo conhecido ${ }^{13}$. Por isso, os dois primeiros anos de produção de geradores se caracterizam por adequações no produto à estrutura industrial instalada $^{14}$.

Pode-se com isso inferir que a acumulação de competência tecnológica para a produção de motores elétricos foi decisiva ao aproveitamento de economias de escopo e, por isso, ajudam a explicar a diversificação para geradores. Em outras palavras, o conhecimento indivisível acumulado (know-how) no processo, mas também no produto, já havia alcançado níveis significativos (capacidade de inovação não incipiente), que implicavam na possibilidade de obtenção de economias de escopo.

A pesquisa que deu suporte a esse artigo (autor, 2018), revelou que um nível não incipiente de capacidade inovadora foi importante para o processo de diversificação

\footnotetext{
${ }^{12}$ Essa foi uma capacidade revelada pela conveniência de utilizar a fundição já instalada, que não fora montada exatamente para produzir o modelo de gerador que se procurava aprender a produzir pela mecanismo de joint venture, destacado acima.

${ }^{13}$ Isso porque parte da tecnologia para produto teve ser adquirida por meio de transferência de tecnologia, o que envolveu a transcrição do protótipo em prancheta de folha vegetal. Já a tecnologia para o processo estava parcialmente internalizada, pelas similaridades do processo para produção de motores, ainda que mudanças significativas como, por exemplo, no projeto inicial da carcaça fossem necessárias.
}

${ }^{14}$ Mas já em 1983, novamente explicado por buscas de reduções de custos e eficiência energética, a empresa passou a realizar mudanças mais significativas em seu processo industrial. Isso se desenvolveu, de um lado, pela estruturação de um conjunto de máquinas e equipamentos específicos para a base produtiva de geradores e, de outro, pela adequação das máquinas e equipamentos que possuíam aplicações comuns não competitivas para as bases produtivas de motores e geradores. Nesse processo, que durou pelo menos até o final da década de 1980, as inovações foram se realizando de forma mais frequente, apontando que a empresa já contava com nível incremental intermediário de capacidade acumulada. 


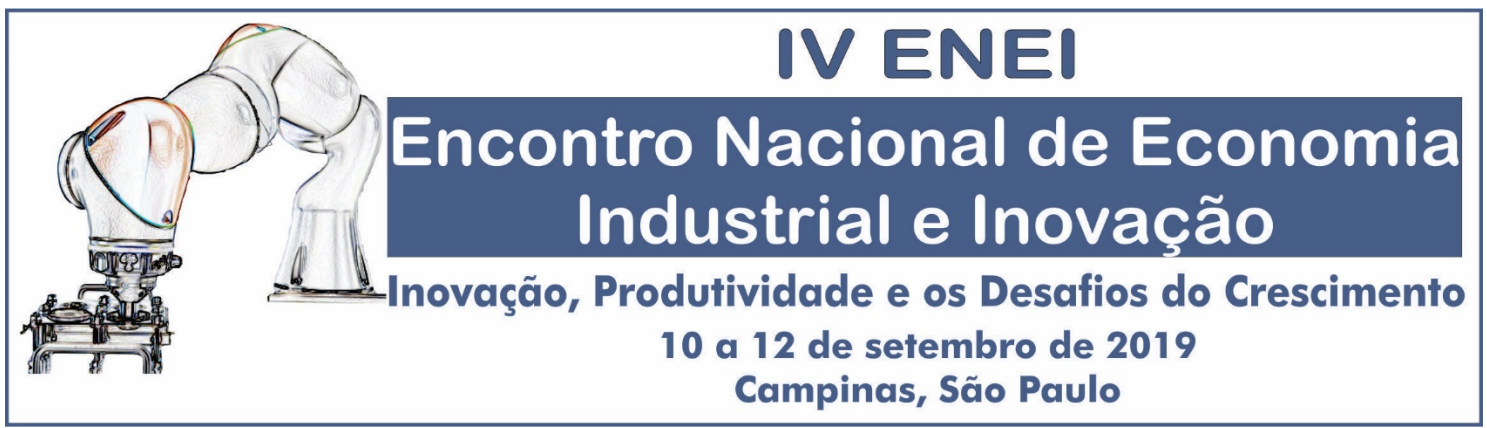

para geradores em pelo menos mais uma dimensão tecnológica. No que se refere a automação do processo (precisão e redução de custos com materiais), viu-se que no momento da diversificação a WEG já contava com capacidade de inovação intermediária/avançada em algumas máquinas, cujo número de fornecedores era restrito à época, tais como as bobineiras, que também implementaram modificações à produção das linhas de geradores da empresa.

A seção seguinte reforça a noção de que o know-how capaz de gerar economias suficientes de escopo advém de um nível não incipiente de capacidade tecnológica. Nela destaca-se a construção de competências em geradores que sustentou diversificação (e aumento da complexidade) para aerogeradores.

4.2. Da Produção de Geradores para a Produção de Aerogeradores.

4.2.1 Os Mecanismos de Aprendizagem para o acúmulo de capacidades em Geradores Elétricos

O processo de acúmulo de competências tecnológicas na base produtiva de geradores também segue a trajetória de busca pelo domínio da dinâmica da inovação.

$\mathrm{Na}$ década de 1980, o destaque a realização de joint venture com a Lloyd Dynamowerke - LDW. Esse mecanismo de aprendizagem gerou a contratação de especialistas para o desenvolvimento de competências em assistência técnica e engenharia, além da realização de treinamentos no exterior nas duas décadas seguintes. Complementarmente, o departamento de P\&D institucionalizado em 1987 foi sempre 


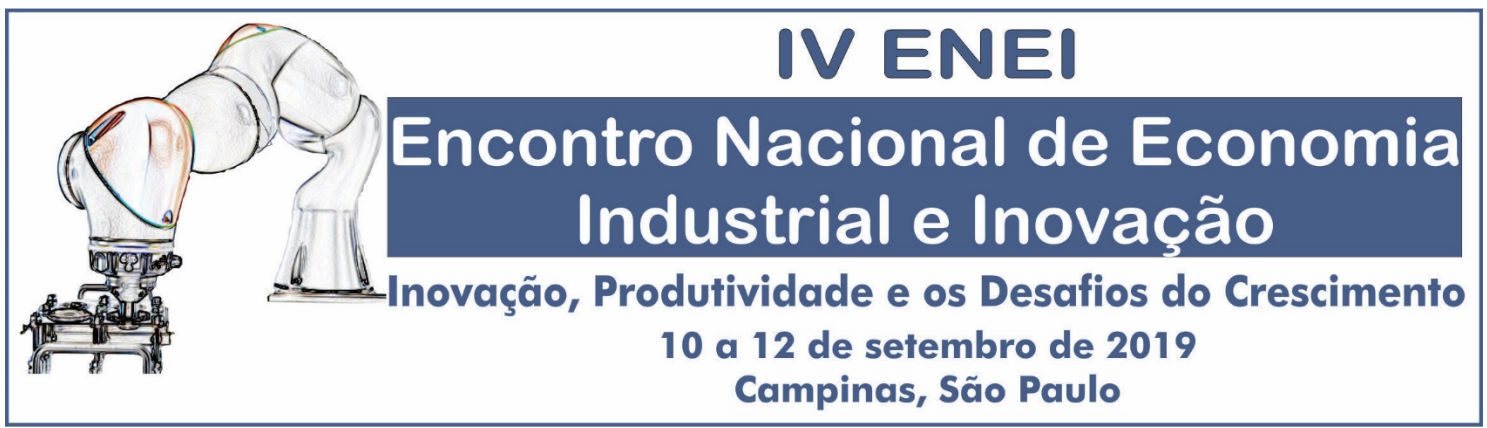

citado como "muito importante" e já tinha como foco "produzir um novo modelo de gerador com tecnologia WEG”, o que ocorreu 3 anos depois, em 1990. Além disso, o laboratório aproximou a empresa da pesquisa universitária, sobretudo da UFSC, também considerada sempre "muito importante" pelos entrevistados ao apoiou ao desenvolvimento de melhorias nas tecnologias nos anos seguintes.

Os esforços envolveram também mecanismos internos de learning by doing, especialmente com engenheiros recém-formados, engenheiros trainees e grupos de supervisão de montagem em atividades rotineiras. Relatou-se ainda contínuo esforço organizacional de treinamento interno de funcionários, sobretudo, voltado à ampliação de competências em ferramentas de microinformática e software de projeto e processo (na segunda metade da década de 1990), mas também tecnicos, em sistemas de qualidade, habilidades técnicas específicas, rotinas de produção e know-how, além outros mais, como habilidades técnicas de upgrade de produto e processo.

Outro objeto dos esforços de aprendizagem foi a codificação, pela absorção da prática de confecção dos manuais da base produtiva de motores, a qual teve sua difusão intensificada, o que gerou importantes feed-backs entre os trabalhadores e especialistas, os quais permitiram aprimoramentos tanto dos manuais como das atividades de trabalho. A evolução dessa rotina, levou aos arquivamento e a normatização da documentação (incluindo desenhos, especificações, relatórios, normas técnicas) em memórias de computadores na década de 1990 e, na década seguinte passou-se a meta informal de codificar todo conhecimento relevante possível, na forma de softwares aplicáveis aos processos produtivos, em substituição a leitura de procedimentos. 


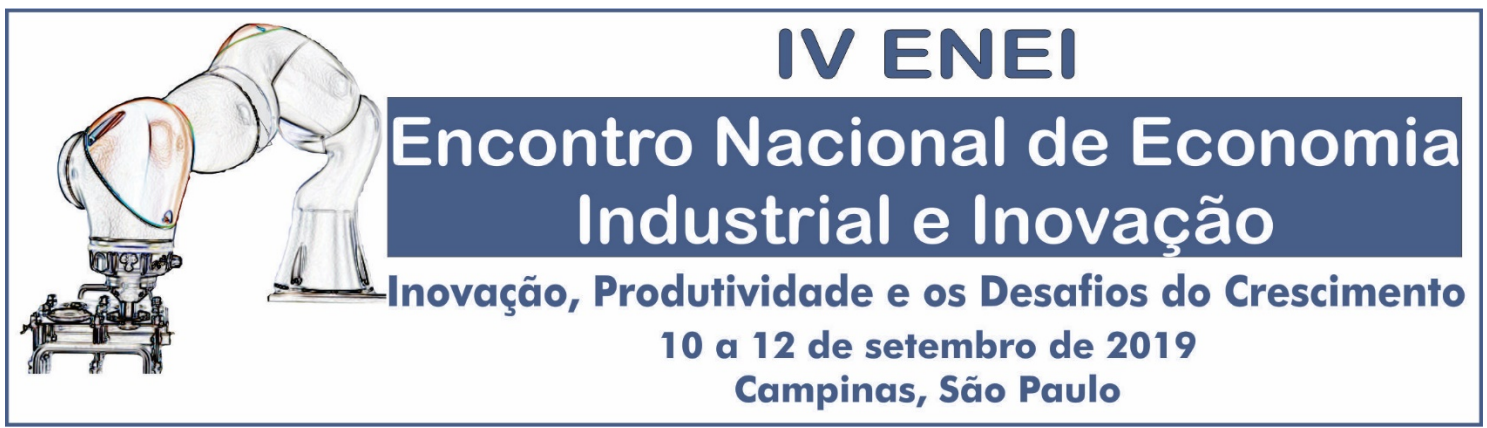

Essa seção procurou ressaltar que, assim como para motores, a decisão de iniciar atividades em geradores foi acompanhada pelo esforço de absorção de conhecimento de ponta na tecnologia a ser utilizada, nesse caso, inicialmente, via joint venture. Também, em linha com a prática para a produção de motores, decidiu-se pela institucionalização de um laboratório de $\mathrm{P} \& \mathrm{D}$, em 1987, que desde os primórdios realizou interações com a esfera universitária (UFSC), algo raro atualmente e raríssimo à época, no SNI brasileiro. Essas práticas foram acompanhadas pelo intenso uso de outros mecanismos complementares de aprendizagem interna e externa a firma, que sustentaram a estratégia da empresa de competir por meio de alta velocidade na absorção dos avanços da fronteira tecnológica mundial no segmento. Daí que dos pequenos melhoramentos e inovações incrementais das décadas de 1980 e 1990, já na década de 2000 e mais intensamente de 2010, a empresa tenha passado a revelar maior capacidade de patenteamento. Enfim, a seções procurou apontar que os esforços de aprendizagem para geradores elétricos não se assemelham aos esforços típicos das emprsas brasileiras, capacidade de produzir ou apenas de realizar inovações adaptativas. Ao contrário, as formas e intensidade do aprendizado apontam uma estratégia agressiva em torno do elevação da capacidade de gerar e gerir mudança tecnológica em geradores elétricos, o que é reforçado pela próxima seção. 


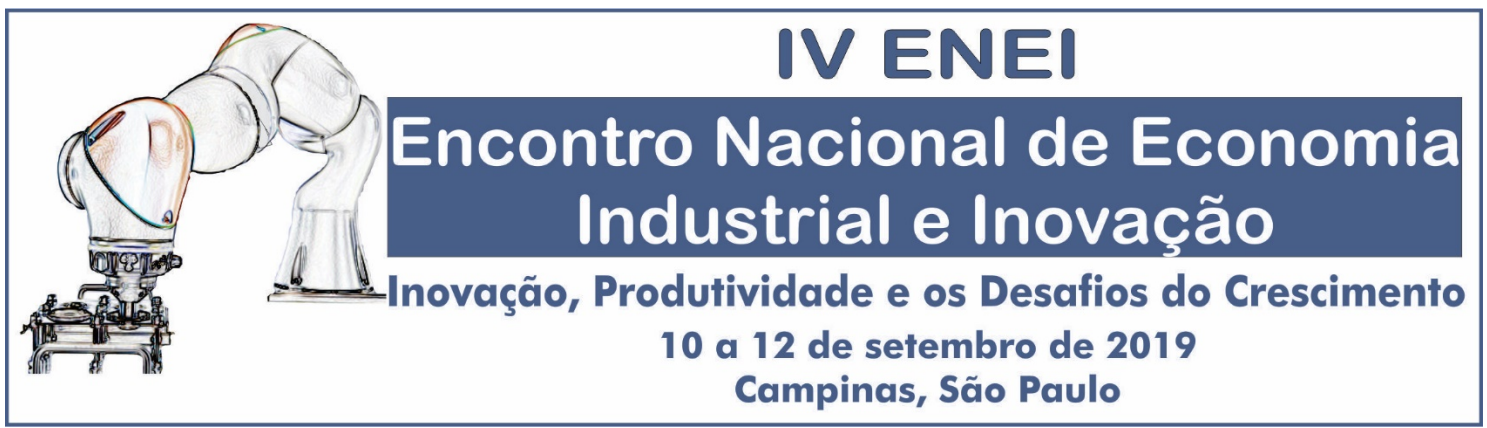

4.2.2 Acumulo de capacidades tecnológicas em Geradores Elétricos e o Aproveitamento de Economias de Escopo que Permitiram a Diversificação para Aerogeradores.

A WEG é uma empresa multiproduto que aproveitou economias de escopo de várias de suas bases produtivas do segmento elétrico para iniciar a produção de aerogeradores, tais como: gerador, transformador, painéis e conversores, além de outras partes do processo como usinagem e caldeiraria ABDI (2017). Por falta de espaço, a seção limita-se a comentários sobre a percepção dos entrevistados sobre a importância do acúmulo de capacidade inovadora em nível não incipiente da WEG no desenvolvimento de geradores para a diversificação produtiva para aerogeradores.

Passadas as primeiras fases, de capacidade de produção e de inovação básica, como visto acima, já em 1987, a WEG iniciou a P\&D em projeto próprio para a nova linha de geradores a diesel, o qual foi lançado no início da década de 1990. Em 1995 iniciou-se a produção dos pequenos hidrogeradores e turbogeradores, produtos significativamente diferente dos tradicionais geradores. Essa capacidade internalizada no laboratório de $\mathrm{P} \& \mathrm{D}$ associada às inovações de maior grau sugerem que na metade da década de 1990 a WEG já operava com um nível intermediário avançado de capacidade tecnológica e que o centro de P\&D fora "absolutamente necessário", nas palavras de um entrevistado.

Durante a década de 2000, o centro de P\&D tentou desenvolver a tecnologia nova, para a produção de turbogeradores, mas sem sucesso. A complexidade 


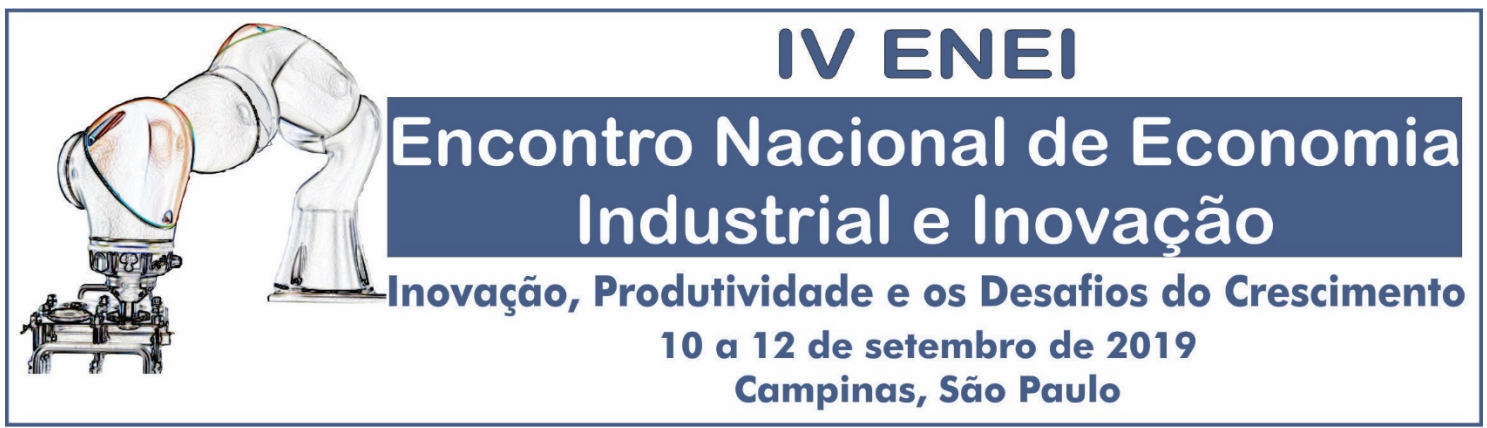

tecnológica da máquina revelou-se superior às capacidades já incorporadas ${ }^{15}$. Não obstante, as competências continuaram se acumulando não apenas pelas tentativas e erros, mas também pelo aprendizado com universidade, fornecedores e clientes. Tal competência fora considerada decisiva à diversificação para aerogeradores. Mas isso poderia passar despercebido, por uma visão superficial do fenômeno.

$\mathrm{Na}$ verdade, a tecnologia para construção dos geradores que equipam os aerogeradores foi em grande medida "adquirida" por outro momento da internacionalização da WEG, a aquisição da norte-americana Northern Power System NPS, detentora da tecnologia e de elevado número de patentes relacionadas à produção dos geradores de imãs permanentes. Contudo, a nuance extremamente relevante é que, segundo os entrevistados da pesquisa de campo, sem a capacidade de inovar de nível incremental avançada acumulada pela WEG, a assimilação da tecnologia de imãs permanentes da NPS levaria 3 ou 4 vezes mais tempo, o que representaria uma desvantagem enorme à entrada no mercado brasileiro, que naquele período assistia rápido crescimento da incipiente capacidade instalada, estimulada pela política energética e industrial local (Araújo e Willcox, 2018). Um dos engenheiros entrevistados estimou que o processo que levou cerca de 18 meses levaria mais de 60, caso não houvesse a capacidade internalizada.

\footnotetext{
15 A complexidade nesse caso envolvia a distribuição da vibração de 3.600 rpms em 2 bobinas e 2 polos ao invés de 4, como nos demais modelos. Essa limitação, foi superada no contexto da internacionalização da WEG, mais especificamente, em 2011 pela aquisição da Eletric Machinery - EM, sedidada em Minneapolis nos EUA. Os esforços de aprendizado em torno dessa tecnologia permitiram WEG alcançar o nível de capacidade arquitetural em geradores.
} 


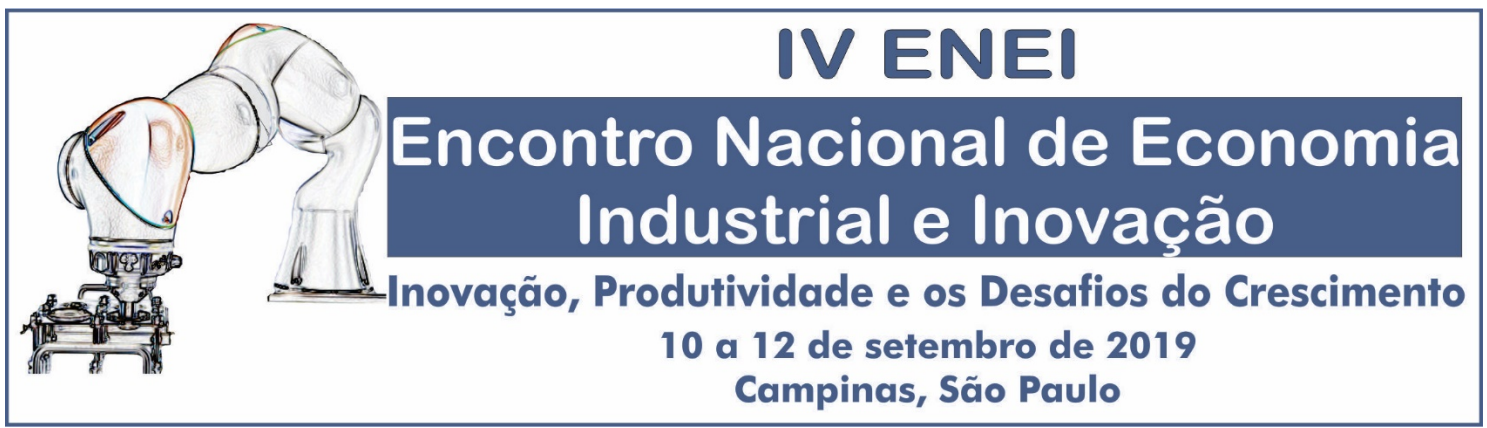

Mais interessante é que tal absorção não envolvera apenas pessoal do centro de $\mathrm{P} \& \mathrm{D}$ e mesmo a formação ocasional de grupos de engenheiros para desenvolvimento de solução de problemas específicos (P\&D ocasional), as entrevistas destacam que o aprendizado acumulado no processo de fabricação de diversas partes do processo, tais como a inserção de bobinas, o balanceamento e mesmo o manuseio de equipamentos pesados foram fundamentais não apenas para a absorção, mas também para que inovações pudessem ser viabilizadas. Este conjunto de competências já internalizadas na produção de geradores no momento da diversificação para aerogeradores foram, portanto, essenciais à geração de inovações na nova tecnologia.

Como derivação, rapidamente os geradores WEG que equiparam os aerogeradores foram objetos de uma série de inovações capazes de reduzir os custos do processo produtivo do projeto original adquirido da NPS ${ }^{16}$.

Nardo (2018) apurou ainda que a capacidade de inovação intermediária avançada conquistada para a produção das máquinas-bobinas foram importantes também para o desenvolvimento dos modelos de geradores que foram acoplados aos

\footnotetext{
${ }^{16}$ Outras formas de obtenção de economias de escopo foram relacionadas, mas menos investigadas. Entre elas destacou-se a capacidade de inovação da "fabrica de ferramentas" ou ferramentaria, por permitir a utilização das mesmas máquinas de formas diferentes. Também fora destacado o acúmulo de capacidade de para deslocamento de grandes equipamentos elétricos, o que inclui a redução dos riscos no transporte de painéis e seus controles, equipamentos altamente caros e sensíveis. Entre as economias de escopo de capital, destacou-se uso de estrutura de gruas já instaladas no parque fabril, capazes de erguer e deslocar grandes peças, também pelo uso dos fios da unidade de trefilação e da estamparia, pelo uso de tornos e fresas. Adicionalmente, a fundição, estamparia, chapa e trefilação processos similares à produção de motores, geradores e aerogeradores, implicaram também obtenção de economias de escopo
} 


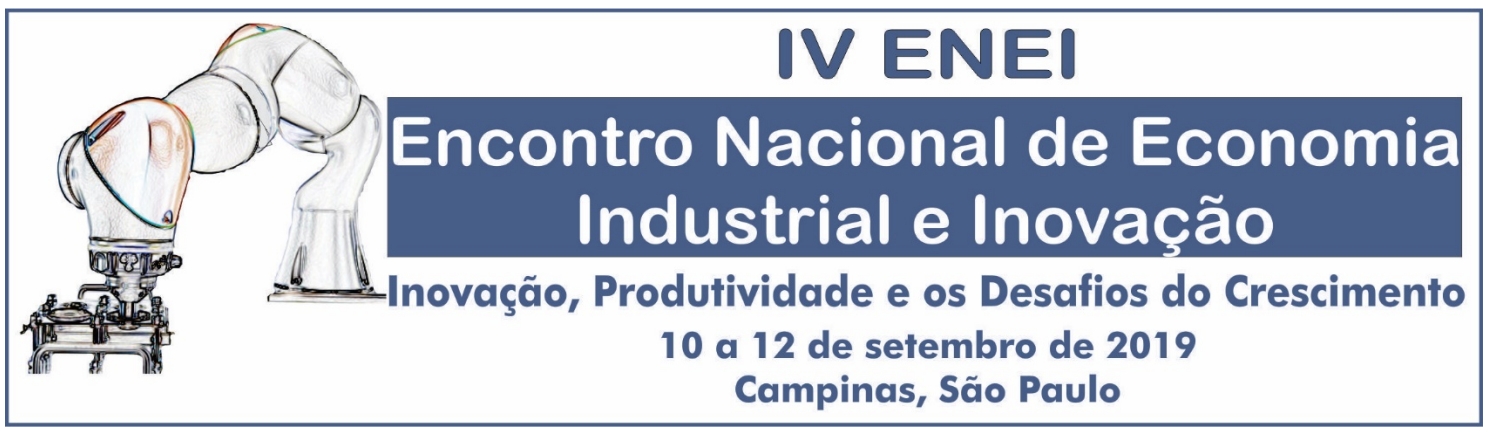

aerogeradores, por implicar em menor tempo para o aprendizado das etapas do processo de produção das bobinas do gerador de imãs permanentes ${ }^{17}$.

\section{CONSIDERAÇÕES FINAIS}

O artigo cumpriu seu objetivo ao mostrar que as economias de escopo de knowhow foram aproveitadas para o processo de diversificação apenas quando a firma já encontrava-se com um nível considerável de capacidade de inovar na base produtiva pré-existente. $\mathrm{O}$ reconhecimento pela empresa do valor dessa capacidade acumulada frente à decisão de diversificar representou uma diminuição do nível de incerteza percebida ao processo. Isso parece ter feito disparar o gatilho da decisão de diversificar. Corrobora a percepção dos entrevistados sobre o elevado grau de importância das competências acumuladas anteriormente para a diversificação: a "muito importante" ou até "essencial".

Notou-se ainda um caminho pelo qual o processo ocorreu. O primeiro passo foi a intenção para aumentar a capacidade de gerar e gerir a mudança tecnológica. A constância nos esforços, mesmo frente a grandes desafios (como inovar inserido em país em desenvolvimento) foi o segundo passo, o qual envolve busca e mesmo construção de fontes de informação e aprendizagem (universidades, joint ventures, criação de centro

\footnotetext{
${ }^{17}$ Nardo (2018) também revelou que outros segmentos da WEG apresentavam capacidade de inovar relativamente avançada, tais como o encapamento de isoladores de mica e outros materiais enrolados diagonalmente em fios rígidos através do uso de $\mathrm{CNC}$ (comando numérico computadorizado). Contudo, a necessidade de finalizar essa pesquisa em determinado período limitou as possibilidades de compreender a forma de suas prováveis contribuições para o processo de diversificação de geradores para aerogeradores.
} 


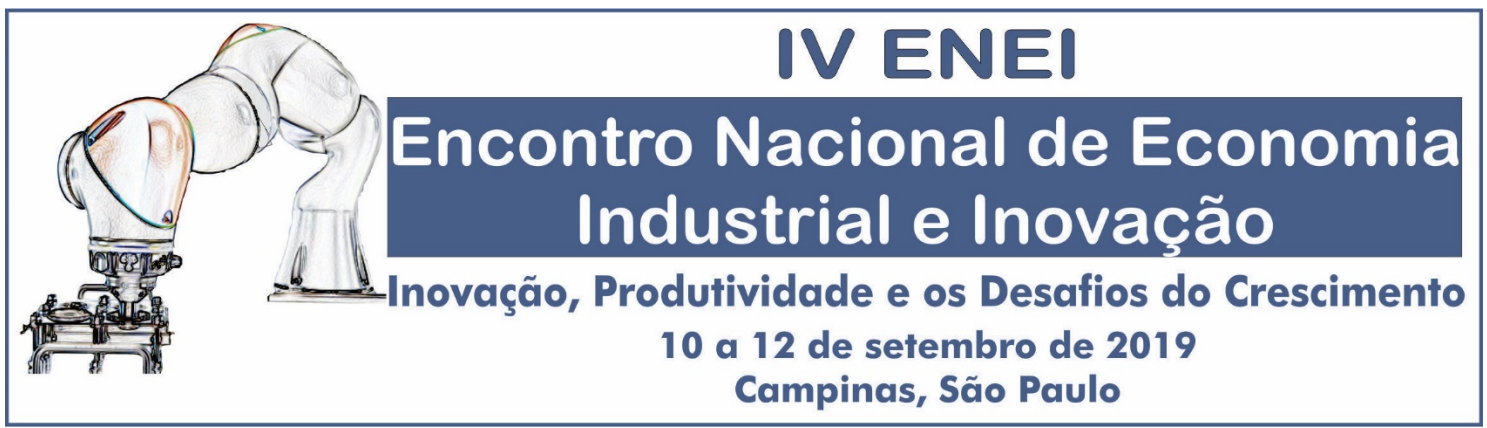

de $\mathrm{P} \& \mathrm{D}$, mas também o uso de outros atores do entorno). $\mathrm{O}$ efetivo acúmulo de capacidade de inovação é o terceiro passo. A percepção sobre a oportunidade tecnológica é o quarto passo, intimamente derivado da percepção sobre as possibilidades de aproveitamento de economias de escopo dinâmica para a diversificação. A realização das economias de escopo é o quinto passo do processo de diversificação que aumenta a complexidade.

Adicionalmente, entende-se que o ferramental metodológico utilizado mostrouse promissor para estudos que procurem aprofundar a relação entre os níveis de competência tecnológica e a diversificação que aumenta a complexidade produtiva ${ }^{18}$.

Os resultados levaram a elaboração da hipótese de que considerando o atraso tecnológico do qual partem as empresas latecomers, o aumento da complexidade produtiva via diversificação surge de estratégias agressivas de aprendizado tecnológico que efetivamente conseguiram avançar significativamente em seus intentos de dominar consistentemente a dinâmica tecnológica pretendida, ou seja, de gerar inovações significativas em uma determinada trajetória tecnológica (Dosi, 1988).

Finalmente, deve-se destacar que tal hipótese tem a pretensão de avançar em uma das causas já sugeridas por Hidalgo e Hausmann (2009) e Hausmann et. al. (2014) para o aumento da complexidade, tais como conhecimento tácito, (um certo nível de acúmulo de capacidades de inovação). Isso não exclui as demais linhas de pesquisa sobre essas causas, também já abordadas em Hidalgo e Hausmann, mas em outras pesquisas, como aquelas que apontam a complementaridade do Estado em impulsionar setores completamente distintos dos já existentes (Chang, 2002).

\footnotetext{
${ }^{18}$ Disponível em Nardo (2018).
} 


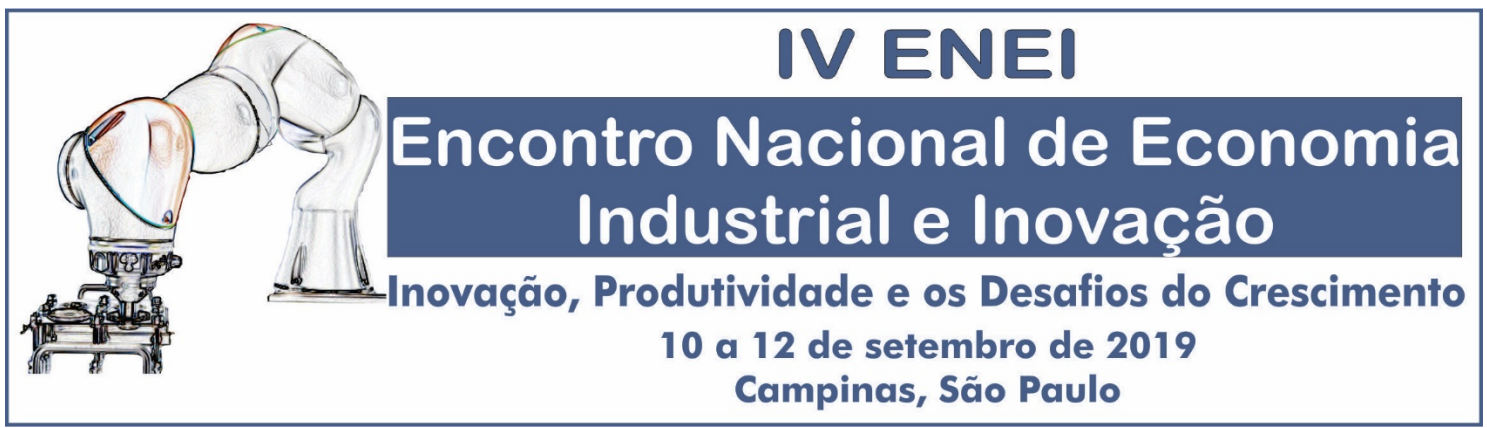

\section{REFERENCIAL BIBLIOGRÁFICO}

AMIT, R.; SCHOEMAKER, P. J. H. Strategic assets and organizational rent. Strategic Management Journal, [s.1.], v. 14, n. 1, p. 33-46, 1993.

ARAÚJO, Bruno Plattek de; WILLCOX, Luiz Daniel. Reflexões críticas sobre a experiência brasileira de política industrial no setor eólico. 2018.

ARIFFIN, N. Internationalisation of technological innovative capabilities: levels, types and speed (learning rates) in the electronics industry in Malaysia. International Journal of Technological Learning, Innovation and Development, 3 (4), 347-391, 2010.

ARIFFIN, N.; FIGUEIREDO, P. Internationalization of innovative capabilities: counter-evidence from the electronics industry in Malaysia and Brazil. Oxford Development Studies, 32 (4), 559-583, 2003.

BELL, M.; FIGUEIREDO, P. N. Innovation Capability Building and Learning Mechanisms in Latecomer Firms: recent empirical contributions and implications for research. Canadian Journal of Development Studies, 33:1, 14-40, 2012.

BELL, M.; PAVITT, K. The Development of Technological Capabilities. In: HAQUE, I. U. Trade, technology and international competitiveness. Washington: The World Bank, 1995.

BRASIL, H. V.; DIEGUES, S.; BLANC, G. Raízes do sucesso empresarial: a experiência de três empresas bem-sucedidas: Belgo Mineira, Metal Leve e WEG S.A. São Paulo, Atlas, 1995.

BRESCHI, Stefano; MALERBA, Franco. Sectoral innovation systems: technological regimes, Schumpeterian dynamics, and spatial boundaries. Systems of innovation: Technologies, institutions and organizations, p. 130-156, 1997.

BRITTO, J. N. P. Diversificação, competências e coerência produtiva. In: KUPFER, D.; HASENCLEVER, L. (orgs). Economia Industrial: fundamentos teóricos e práticas no Brasil. Rio de Janeiro: Campus, Cap. 14. p. 307-343, 2002.

CHANG, H. Kicking Away the Ladder: Development strategy in Historical Perspective, 256 p., 2002.

CHANG, H.; ANDREONI, A. Industrial policy and the future of manufacturing. Economia e Politica Industriale: Journal of Industrial and Business Economics. Vol. 43, issue 4, 491-502, p.2016.

COASE, R. H. The nature of the firm. Economica, New Series, v. 4, n. 16, p. 386-405, Nov. 1937. 


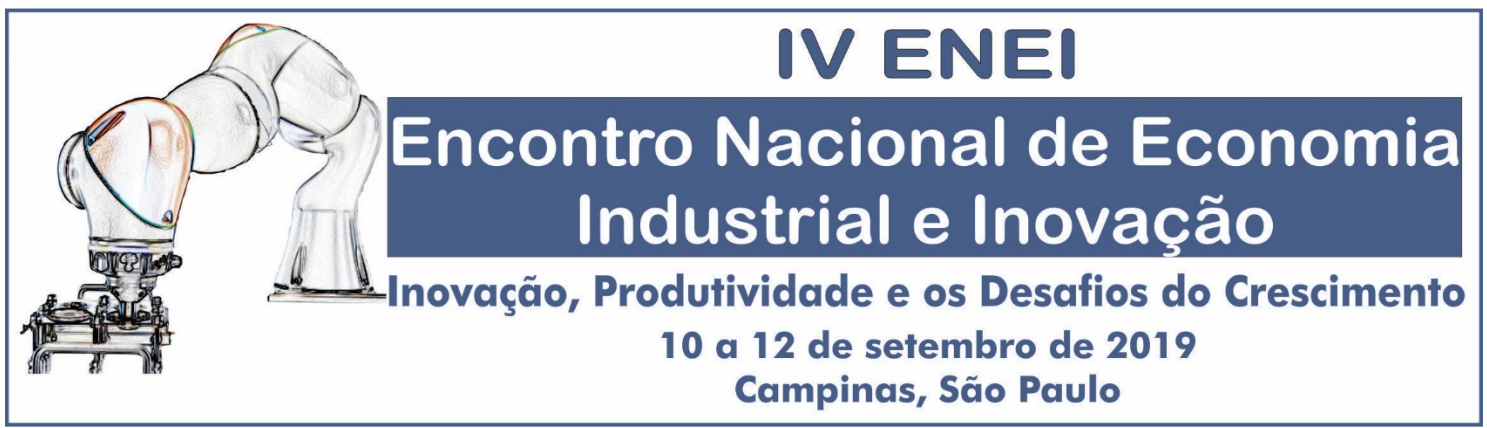

44, Oct. 1960.

The problem of social cost. Journal of Law and Economics, v. 3, p. 1-

DOSI, G. Institutions and markets in a Dynamic World. The Manchester School of Economic \& Social Studies, vol. 56, issue 2, 119-46, 1988.

FIANI, R. Teoria dos custos de transação. In: KUPFER, D.; HASENCLEVER, L. (orgs). Economia Industrial: fundamentos teóricos e práticas no Brasil. Rio de Janeiro: Elsevier, Cap. 12, p. 267-286, 2002.

FIGUEIREDO, P. N. Trajetórias de acumulação de competências tecnológicas e os processos subjacentes de aprendizagem: revisando estudos empíricos. Revista de Administração Pública, Rio de Janeiro 34(1),7-33, 2000.

Aprendizagem tecnológica e inovação industrial em economias emergentes: Uma breve contribuição para o desenho e implementação de estudos empíricos e estratégias no Brasil. Revista Brasileira de Inovação, v. 3, n. 2, p. 323$361,2004$.

Gestão da Inovação: Conceitos, Métricas e Experiências de Empresas no Brasil. [Reimpr.] Rio de Janeiro: Editora LTC, 2013.

FREEMAN, C.; SOETE, L. A Economia da Inovação Industrial. Campinas, ed. Unicamp, 2008.

HAUSMANN, R. et. al. The Atlas of Economic Complexity: Mapping Paths to Prosperity. MIT Press. 2014.

HAUSMANN, R.; KLINGER, B. The structure of the product space and the evolution of comparative advantage. Center for International Development at Harvard University (CID), Working Paper No. 146, 2007.

HAUSMANN, R.; HWANG, J.; RODRIK, D. What you export matters. Journal of Economic Growth, v. 12, n. 1, p. 1-25, 2006.

HIDALGO, C. A. HAUSMANN, R. The building blocks of economic complexity. Proceedings of the National Academy of Sciences (PNAS). v. 106, n. 26, p. 1057010575, june 2009.

HIDALGO, C. A.; KLINGER, B.; BARABÁSI, A. -L.; HAUSMANN, R. The product space conditions the development of nations. . Science, v. 317, n. 5837, p. 482-487, 2007.

KATZ, J. Domestic technology generation in LCDs: a review of research findings. (Buenos Aires: IDB/ECLA Research programme in science and technology). Working paper $\mathbf{n}^{\mathbf{0}} \mathbf{3 5}, 1980$.

KIM, L. Stages of development of industrial technology in aa developing country: A model. Research Policy, v. 9, n. 3, p. 254-277, 1980. 


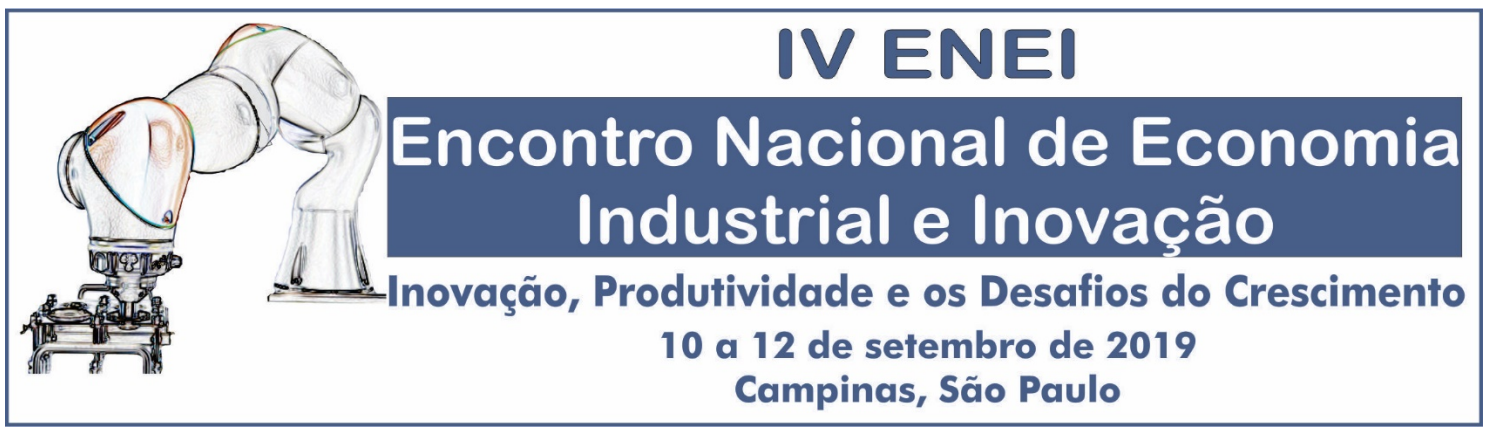

LALL, S. Technological Capabilities and Industrialization. World Development, Vol. 20, No. 2, pp. 165-186,1992.

LUNDVALL, Bengt-Åke (Ed.). National systems of innovation: Toward a theory of innovation and interactive learning. Anthem press, 2010.

MATHEUS, J. A. A resource-based view of Schumpeterian economic dynamics. Journal of Evolutionary economics, 12(1), 29-54, 2002.

MONTGOMERY, C. Corporate Diversification. The Journal of Economic Perspectives, v. 8, n. 3, p. 163-178, 1994.

MORAES, J. C. de. A trajetória de crescimento da WEG: A folga de recursos humanos como propulsora de crescimento da firma. Dissertação (Mestrado em Administração) - Universidade Federal do Rio de Janeiro -UFRJ, Instituto de PósGraduação em Administração - COPPEAD, 2004.

NARDO, A. P. V. A construção das capacidades tecnológicas como fundamento da diversificação: O caso da WEG S.A. Tese (Doutor em Economia)-Universidade Federal de Santa Catarina. Florianópolis, 349 f.,2018.

NÜBLER, Irmgard. A theory of capabilities for productive transformation: Learning to catch up. Transforming Economies: Making industrial policy work for growth, jobs and development. United Nations (UNCTAD) and International Labour Organization, 2014.

PENROSE, E. The Theory of the Growth of the Firm. New York: John Wiley, 1959. PINHEIRO, M. C. et. al. Acumulação de capacidades tecnológicas, inovação e competitividade industrial: alguns resultados para a indústria: alguns resultados para a indústria brasileira de petróleo e gás. Rio de Janeiro: EBAPE/FGV, 2017.

SCHMITZ, A. WEG 40 anos. Jaraguá do Sul: Weg Indústrias S.A., 2001.

TEECE, D. J. Economies of scope and the scope of the enterprise. Journal of Economic Behavior and Organization, v. 1, no. 3, p. 223-247, 1980.

D. J. An economic theory of multiproduct firms. Journal of Economic

Behavior and Organization, v. 3, p. 39-63, 1982.

TERNES, A. História da WEG: 25 anos. Joinville: Gráfica Meyer S.A., 1986.

. WEG: 36 anos de história. Joinville: Gráfica e Editora Pallotti, 1997.

VIDIGAL, A. WEG 50 anos: um caminho sustentável. Editora DBA Dórea Books and Art, 2011.

WILLIG, R. Multiproduct technology and market structure. American Economic Review, v. 69, n. 2, p. 346-351, may 1979. 


IV ENEI
Industrial e Inovação
10 a 12 de setembro de 2019
Campinas, sáo Paulo

ANEXO 


IV ENEI
Industrial e InOvação
Inovação, Produtividade e os Desafios do Crescimento
10 a 12 de setembro de 2019
Campinas, sáo Paulo

Quadro 1 - Níveis de capacidade tecnológica para motores e geradores elétricos para a WEG.

\begin{tabular}{|c|c|c|}
\hline \multirow{2}{*}{$\begin{array}{l}\text { NÍVEIS DE ACUMULAÇÃO DE CAPACIDADES } \\
\text { TECNOLÓGICAS }\end{array}$} & \multicolumn{2}{|c|}{ EFICIÊNCIA ENERGÉTICA EM PRODUTO E MATERIAIS } \\
\hline & MOTORES ELÉTRICOS & GERADORES ELÉTRICOS \\
\hline \multicolumn{3}{|c|}{ CAPACIDADE DE PRODUÇÃO } \\
\hline $\begin{array}{l}\text { A empresa aprende todas as qualificações para apenas } \\
\text { produzir, com a melhor qualidade possivel, mas não é nada } \\
\text { inovativa. }\end{array}$ & $\begin{array}{l}\text { - Reprodução dos produtos a partir de manuais de normas estabelecidas } \\
\text { (1961); } \\
\text { - Aquisição de pacotes tecnológicos para implantação de produto, com acesso } \\
\text { a assessoria para reprodução de plantas e projetos; } \\
\text { - Fornecimento regional (SC e RS). }\end{array}$ & $\begin{array}{l}\text { - Replicação do produto seguindo especificações do pacote tecnológico adquirido } \\
\text { (1980); } \\
\text { - Controle de qualidade por inspeção ou reclamação dos clientes. }\end{array}$ \\
\hline \multicolumn{3}{|c|}{ CAPACIDADE DE INOVAÇÃO: Capacidade para gerar e gerir mudança tecnológica. } \\
\hline $\begin{array}{l}\text { (1) BÁSICA: Pequenas alterações em processos de } \\
\text { produção, produtos e/ou equipamentos com base em } \\
\text { imitação ou cópia de tecnologias existentes. }\end{array}$ & $\begin{array}{l}\text { - Pequenas alterações no produto para reduzir uso de materiais, visando } \\
\text { redução de custos e ganho de competitividade (1962 - 1970); } \\
\text { - Fornecimento regional (SC e RS) e ganho de mercado no interior paulista. }\end{array}$ & $\begin{array}{l}\text { - Replicações de especificações determinadas pelos clientes (1981 e 1982); } \\
\text { - Pequenas adaptações da tecnologia já existente(1981 e 1982); } \\
\text { - Implementar controle de qualidade como rotina na produção; }\end{array}$ \\
\hline $\begin{array}{l}\text { (2)INCREMENTAL INTERMEDIÁRIO: Corresponde a } \\
\text { pequenas melhorias nos componentes e elementos } \\
\text { individuais da tecnologia existente, mas as relações entre } \\
\text { os componentes permanecem inalteradas. }\end{array}$ & $\begin{array}{l}\text { - Modificações sutis no produto que o tornam mais eficiente, sem } \\
\text { descaracterizar o projeto (1962 - 1970); } \\
\text { - Pesquisa em novos materiais para redução de custos e maior resistência; } \\
\text { - Fornecimento ao mercado doméstico. }\end{array}$ & $\begin{array}{l}\text { - Realização de modificações na qualidade dos materiais e/ou na quantidade } \\
\text { utilizada destes insumos (1983): } \\
\text { * Redução de custos de produção. } \\
\text { * Aumento da resistência da máquina; } \\
\text { * Redução do ruído ou da vibração. }\end{array}$ \\
\hline
\end{tabular}




IV ENEI
Industrial e InOvação
Inovação, Produtividade e os Desafios do Crescimento
10 a 12 de setembro de 2019
Campinas, sáo Paulo

(3) INCREMENTAL AVANÇADA: Introduz novos produtos, processos e/ou sistemas de equipamentos, sem alterar as relações entre os elementos da tecnologia.

(4) ARQUITETURAL: Compreende as alterações nas relações entre os elementos da tecnologia, seja em produtos ou sistemas, sem que os componentes individuais sejam modificados.

(5) RADICAL OU MUNDIAL: Estabelece um conceito novo para o mercado mundial, em que novos componentes e elementos são combinados de uma forma diferente formando uma arquitetura nova. Trata-se de novidade para o mundo.

Fonte: Elaboração própria com base em Figueiredo (2013).
- Pesquisa em novos materiais para diversas aplicações (a partir de 1970); - Novas linhas de produto, com diferenciação do produto para modelos maiores e mais potentes, dada a tecnologia existente (a partir de 1970);

- Modificações na mecânica que incorrem em maior rendimento tecnológico (a partir de 1970);

- Fornecimento a mercados exportadores.

- Desenho original via E, P e D em termos da densidade de potência (2010): *Redução do tamanho do produto para determinada potência.

- Modificações dos materiais envolvidos nas partes do produto (2010): *Rotor de imãs permanentes.

- Desenho e desenvolvimento de produtos em classe mundial: *Ex: Invenção do motor elétrico de corrente alternada.
Engenharia e operação para desenvolvimento de novos produtos (1987/88) - Realização de diferenciação:

* Novas linhas de produto $(1990$ - 1995);

* Para uma dada tecnologia, a empresa passa a oferecer produtos maiores e mais potentes, dentro da mesma linha de produtos (fins de $1990 \mathrm{em}$ diante).

- Desenvolvimento de produtos e soluções de tecnologias de última geração, de alta complexidade;

- Elaboração de novas especificações (experimento em escala piloto, visando desenho e desenvolvimento de produtos complexos e de alto valor agregado):

* Redução das máquinas para uma dada potência (densidade de potência). * Domínio da tecnologia do turbogerador 2 polos (2011).

- Integração com o mercado global;

- Desenho e desenvolvimento de produtos em classe mundial. 